\title{
Recuperação de resíduos de embalagens cartonadas através da pirólise: um
} estudo bibliométrico

\section{Carton packages waste recovery by pyrolysis: a bibliometric study}

Recuperación de residuo de envases de cartón mediante pirólisis: un estudio

\section{bibliométrico}

Recebido: 21/04/2020 | Revisado: 23/04/2020 | Aceito: 29/04/2020 | Publicado: 06/05/2020

\section{Diunay Zuliani Mantegazini}

ORCID: https://orcid.org/0000-0003-0606-5991

Universidade Federal do Espírito Santo, Brasil

E-mail: diunayzmantegazini@gmail.com

Thiago Padovani Xavier

ORCID: https://orcid.org/0000-0001-7148-9921

Universidade Federal do Espírito Santo, Brasil

E-mail: thiago.p.xavier@ufes.br

Marcelo Silveira Bacelos

ORCID: https://orcid.org/0000-0002-0838-6839

Universidade Federal do Espírito Santo, Brasil

E-mail: marcelo.bacelos@ufes.br

\section{Resumo}

A análise bibliométrica é um método que possibilita avaliar quantitativamente a produção acadêmica através da análise de documentos existentes. Este artigo teve como objetivo analisar as características das publicações relacionadas ao tema recuperação de resíduos cartonados através da pirólise. A pesquisa foi realizada na base de dados Web of Science (WOS) do Clarivate Analytics. Inicialmente foi realizada a busca por artigos que contém a palavra "Pyrolysis" em seu tópico, posteriormente, foi realizado um refinamento dos artigos adicionando o termo "Carton Packages" e "Tetra Pak". Para realizar as análises, foi utilizada a ferramenta "Analisar resultados" fornecida pela Web of Science (WOS) permitindo gerar informações relacionadas ao número de publicações, países, áreas de pesquisas e tipos de publicações, além dos softwares VOSviewer e CiteSpace possibilitando a criação de redes de 
coautoria de organização, coautoria de países, coautoria de autores, cocitação de referências, cocitação de periódicos e coocorrência de palavras-chave e por fim, sendo realizada uma Matriz SWOT (Strenghts, Weaknesses, Opportunities e Threats). A partir do termo "Pyrolysis" foram encontradas 101.368 publicações, sendo 8.974 no último ano. Dentre os países com maior número de publicações sobre o tema, destacam-se a China e os Estados Unidos. Adicionando os termos "Carton Packages" e "Tetra Pak" foram encontradas 23 publicações, sendo o maior número encontrado no ano de 2018. Além disso, o Brasil é o país com o maior número de publicações. Isso mostra que, nos últimos anos foram realizadas inúmeras pesquisas sobre o tema recuperação de resíduos cartonados através da pirólise, com o objetivo de melhorar a eficiência dos processos e que permitam ampliar as escalas de produção. $\mathrm{O}$ aumento de interesse se dá, devido à necessidade em buscar soluções para a diminuição do impacto ambiental e gerenciamento dos resíduos sólidos, causado pelo descarte inadequado do mesmo. Além do ponto de vista econômico, possibilitando a geração de produtos com alto valor agregado.

Palavras-chave: Bibliometria; VOSviewer; CiteSpace; Pirólise; Embalagens Cartonadas.

\begin{abstract}
Bibliometric analysis is a method that possible to quantitatively evaluate academic production through the analysis of existing documents. This article aimed to analyze the characteristics of publications related to the theme of carton packages waste recovery through pyrolysis. The research was carried out in the Web of Science (WOS) database of Clarivate Analytics. Initially, a search was made for articles that contain the word "Pyrolysis" in its topic, subsequently the articles were refined by adding the term "Carton Packages" and "Tetra Pak". To perform the analyzes, the tool "Analyze results" was used provided by the Web of Science (WOS), allowing to generate information related to the number of publications, countries, research areas and types of publications, in addition to the VOSviewer and CiteSpace software enabling the creation of networks for organization co-authorship, country co-authorship, author co-authorship, reference co-citation, journal co-citation and keyword co-occurrence and finally, a SWOT Matrix (Strengths, Weaknesses, Opportunities and Threats) was performed. From the term "Pyrolysis" 101.368 publications were found, 8.974 of which were in the last year. Among the countries with the largest number of publications on the topic can highlight China and the United States. Adding the terms "Carton Packages" and "Tetra Pak", 23 publications were found, the largest number being found in the year 2018. In addition, Brazil is the country with the largest number of publications. This shows
\end{abstract}


that in recent years, numerous researches have been carried out on the theme carton packages waste recovery through Pyrolysis, with the objective of improving the efficiency of the processes and allowing expanding the production scales. The increase in interest is due to the need to search solutions to reduce the environmental impact and management of solid waste, caused by its inadequate disposal. Furthermore to the economic point of view, enabling the generation of products with high added value.

Keywords: Bibliometric; VOSviewer; CiteSpace; Pyrolysis; Carton packages.

\section{Resumen}

El análisis bibliométrico es un método que permite evaluar cuantitativamente la producción académica a través del análisis de documentos existentes. Este artículo tuvo como objetivo analizar las características de las publicaciones relacionadas con el tema recuperación de residuos de cartón mediante pirólisis. La investigación se realizó en la base de datos Web of Science (WOS) del Clarivate Analytics. Inicialmente, la búsqueda de artículos que contenían la palabra "Pyrolysis" en tu tema, más tarde, los artículos se refinaron agregando el término "Carton Packages" y "Tetra Pak". Para realizar los análisis, se utilizó la herramienta "Analizar resultados" proporcionada por la Web of Science (WOS) para generar información relacionada con la cantidad de publicaciones, países, áreas de investigación y tipos de publicaciones, además del software VOSviewer y CiteSpace, que permite la creación de redes de coautoría de la organización, coautoría del país, coautoría de los autores, co-cita de referencias, co-citación de revistas y co-ocurrencia de palabras clave y, finalmente, una matriz SWOT (Strenghts, Weaknesses, Opportunities y Threats). Del término "Pyrolysis"se encontraron 101,368 publicaciones, de las cuales 8,974 fueron en el último año. Entre los países con mayor número de publicaciones sobre el tema, China y Estados Unidos se destacan. Añadiendo los términos "Carton Packages" y "Tetra Pak", se encontraron 23 publicaciones, la mayor cantidad encontrada en el año 2018. Además, Brasil es el país con la mayor cantidad de publicaciones. Esto muestra que, en los últimos años, se han llevado a cabo numerosas investigaciones sobre el tema de la recuperación de residuos de cartón mediante pirólisis, con el objetivo de mejorar la eficiencia de los procesos y permitir la expansión de las escalas de producción. El aumento en el interés se debe a la necesidad de buscar soluciones para reducir el impacto ambiental y la gestión de los residuos sólidos, causados por su eliminación inadecuada. Además del punto de vista económico, permite la generación de productos con alto valor agregado.

Palabras clave: Bibliométrica; VOSviewer; CiteSpace; Pirólisis; Paquetes de cartón. 


\section{Introdução}

Fatores como a mudança climática global, poluição ambiental, redução dos recursos naturais e a geração de resíduos sólidos provenientes de processos industriais e atividades humanas fazem com que a energia renovável seja um tema de crescente importância.

Dentre esses resíduos sólidos, podemos citar as embalagens cartonadas. Sua estrutura de compósito laminar é formada por papel, polietileno e alumínio. O papel proporciona estabilidade e resistência, já o polietileno protege contra a umidade externa e permite que o papel grude na folha de alumínio, enquanto o alumínio protege o alimento contra a entrada de oxigênio e de luz (Tetra Pak, 2020). Essa combinação de papeis revestidos com polietileno e alumínio geram grandes impactos ambientais em detrimento da difícil desagregação e degradação dos materiais constituintes em condições naturais.

Dentre os processos de recuperação das embalagens cartonadas, a pirólise surge como uma tecnologia verde para separar o alumínio do polietileno, permitindo que ambas as matérias-primas possam ser usadas na fabricação de novas embalagens cartonadas (Melo, et al., 2016). Para o processo de pirólise de resíduos de embalagens, os principais tipos de reatores que se adequam ao processo são o leito de jorro e o leito fluidizado. Estes equipamentos proporcionam uma mistura intensa entre os materiais, ocasionando grandes áreas de contato seguidas de taxas elevadas de transferência de calor e massa.

Conforme relatado na literatura, a pirólise de resíduos cartonados vem sendo estudada por diversos pesquisadores. Wu \& Chang (2001), Korkmaz et al. (2009), De Marco et al. (2009) e Alvarenga et al. (2012), observaram a partir de estudos sobre pirólise de embalagens cartonadas em atmosfera inerte, que os produtos do processo são alumínio com alto grau de pureza e parafina.

Recentemente, estudos realizados por um grupo de pesquisadores brasileiros tem contribuído para secagem e pirólise de resíduos de embalagens cartonadas, Bacelos et al. (2009), Alvarenga et al. (2012), Marques et al. (2012), Marques \& Bacelos (2013), Melo et al. (2016), Alvarenga et al. (2016), Freitas et al. (2017) lidando com rotas de recuperação e com a tecnologia de pirólise para a recuperação do alumínio e parafina das embalagens cartonadas pós-consumo.

A análise bibliométrica é um método útil para identificar tendências de pesquisa e questões importantes com base em informações de publicações históricas (Ye, et al., 2014). Dada à importância deste tema, o presente estudo tem como objetivo explorar a literatura acadêmica existente sobre a recuperação de resíduos cartonados através da pirólise. 
(CC BY 4.0) | ISSN 2525-3409 | DOI: http://dx.doi.org/10.33448/rsd-v9i7.3827

Mostrando uma visão geral dos resultados encontrados até o momento, utilizando-se, de softwares e de ferramentas estatísticas para expor de maneira clara e objetiva os resultados aos leitores.

\section{Metodologia}

Realiza-se uma pesquisa em bases da web como considera Pereira et al. (2018). Para realizar a análise bibliométrica, foi utilizada à base de dados da plataforma Web of Science (WOS) do Clarivate Analytics, que é um dos bancos de dados mais amplamente utilizados em tais estudos. O primeiro passo (Figura 1) foi à busca por artigos que possuíssem a palavra "Pyrolysis" em seus tópicos publicados entre os anos 1945 e 2019.

No segundo passo, foi realizado um refinamento dos artigos encontrados com o tema "Pyrolysis", para isso foram adicionados os termos "Carton Packages" e "Tetra Pak". Para realizar as análises, foi utilizada a ferramenta "Analisar resultados" fornecida pela Web of Science (WOS) que permitiu gerar informações relacionadas ao número de publicações, países, áreas de pesquisas e tipos de publicações, além dos softwares VOSviewer e CiteSpace.

Figura 1. Fluxograma do processo de seleção dos artigos.

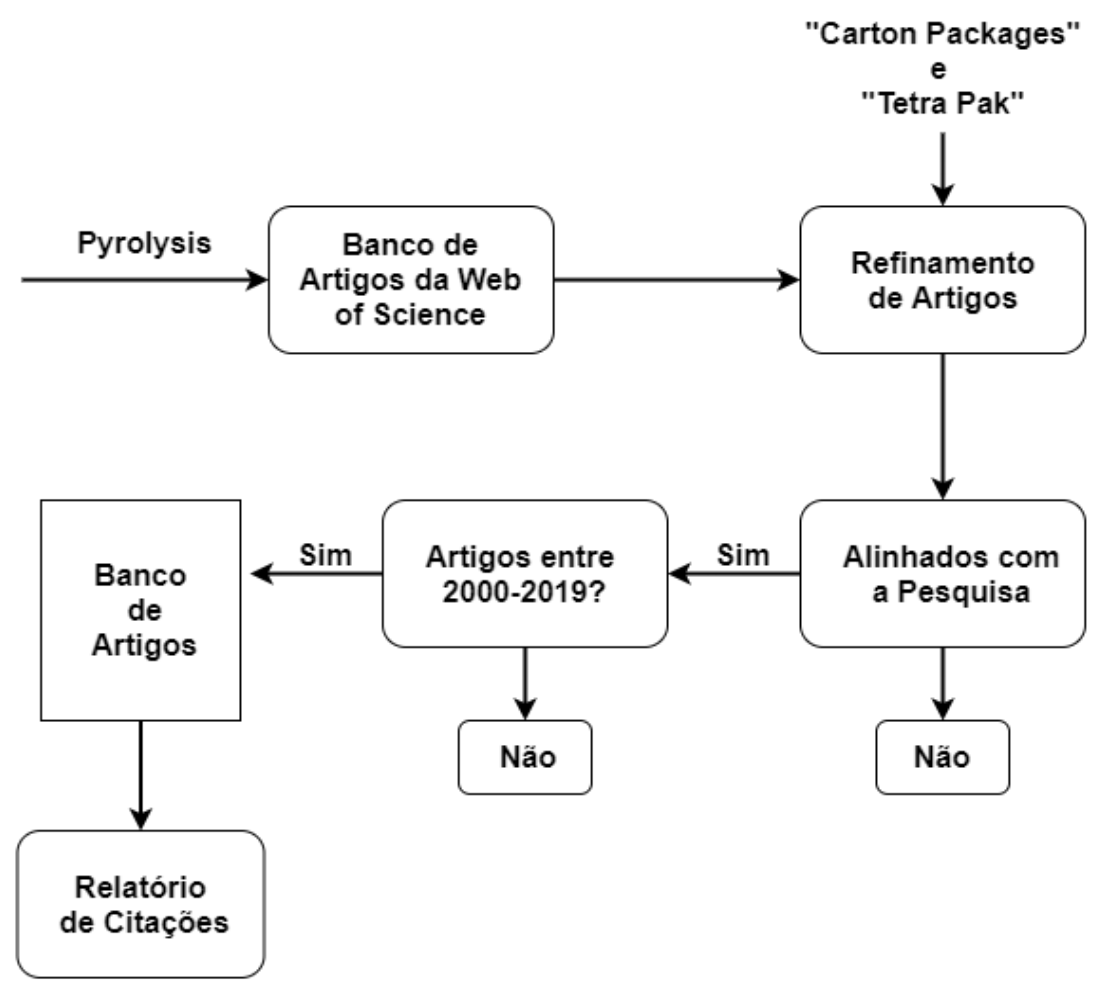

Fonte: Autoria própria, 2020. 
Com a utilização do software de análise bibliométrica VOSviewer, foram plotadas redes de coautoria de organização, cocitação de referências e coocorrência de palavras-chave (Van Eck \& Waltman, 2010). O VOSviewer é uma ferramenta robusta que utiliza algoritmos e funcionalidades de clusters com base nos pontos fortes das conexões entre os itens para ajudar na análise da rede (Romanelli, et al., 2018).

O tamanho dos nós e da fonte do rótulo representam a frequência de cada tópico, quanto maior o nó e a fonte, mais frequente o tópico (Li \& Hale, 2016). Já com a utilização do software de análise bibliométrica CiteSpace, redes de coautoria de países, cocitação de periódicos, coautoria de autores, além das áreas de pesquisas foram plotadas.

Os artigos foram ordenados dos mais citados para os menos citados, para que em seguida, fosse realizada a leitura dos artigos com maior relevância encontrado na Web of Science (WOS), obtidos nas pesquisas sobre a recuperação de resíduos cartonados através da pirólise. Por fim, foi realizada uma Matriz SWOT (Strenghts, Weaknesses, Opportunities e Threats) com a finalidade de auxiliar na análise exploratória dos pontos fracos e fortes, além de ameaças e oportunidades em relação à recuperação de resíduos cartonados através da pirólise.

\section{Resultados e Discussão}

\subsection{Características das publicações com o Tópico "Pyrolysis"}

A partir do termo "Pyrolysis" no banco de dados da Web of Science (WOS) do Clarivate Analytics, foram encontradas 101.368 publicações. A primeira publicação ocorreu em 1945 com o tema "Naphthene pyrolysis for butadiene", na revista Industrial and Engineering Chemistry, volume 37, $4^{\circ}$ edição, pelos autores Berg, L., Sumner, G.L., Montgomery, C.W., Coull, J.

A evolução das publicações entre 1995 a 2019 relacionadas ao tema "Pyrolysis" é notável, dada à importância e vantagens oferecidas pelos processos de pirólise com a finalidade de obtenção de bioprodutos (Figura 2). 
Figura 2. Publicações por ano com o tema "Pyrolysis".

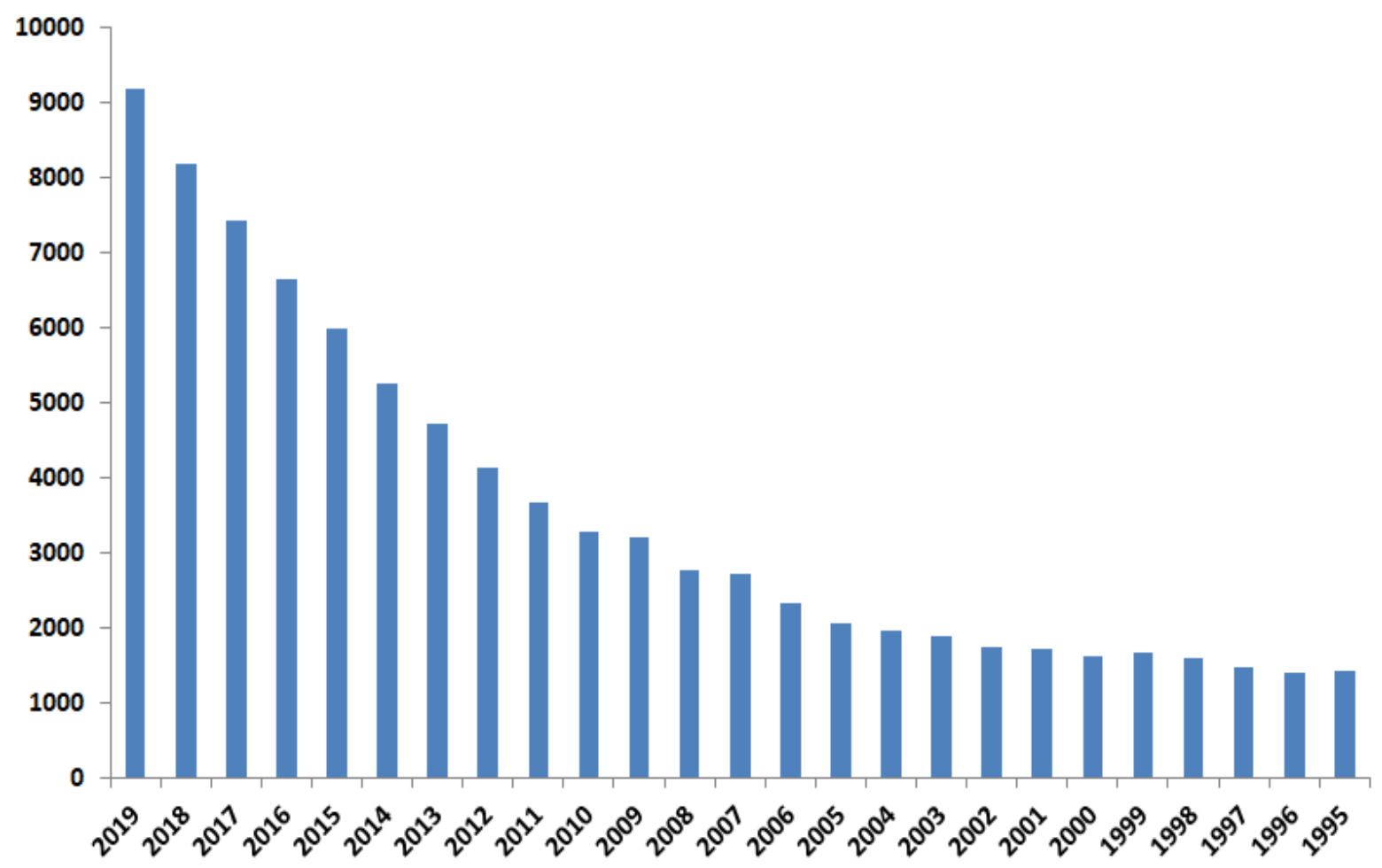

Fonte: Plataforma Web of Science, 2020.

As publicações sobre o tema "Pyrolysis", entraram em uma fase de expansão na ultima década, devido a crescente importância da energia renovável em satisfazer as preocupações ambientais sobre o uso de combustíveis fósseis e sua contribuição para o efeito estufa (Bridgwater, et al., 1999).

O maior número de publicações ocorreu no ano de 2019, contabilizando 8,974 publicações no total. Em outras palavras, aumentou três vezes em comparação ao ano de 2008, o que sugere grande discussão/preocupação sobre o tema.

A quantidade de publicações sobre o tema mostra uma tendência crescente, que pode ser dividida da seguinte forma: (1) período de estagnação (1995-2005); (2) período exponencial (2006-2019), atingindo nesse período o pico no ano de 2019.

Os países que mais realizaram publicações com o tema "Pyrolysis" foram a China, os Estados Unidos e o Japão, respectivamente (Figura 3). 
Research, Society and Development, v. 9, n. 7, e144973827, 2020

(CC BY 4.0) | ISSN 2525-3409 | DOI: http://dx.doi.org/10.33448/rsd-v9i7.3827

Figura 3. Publicações por países com o tema "Pyrolysis".

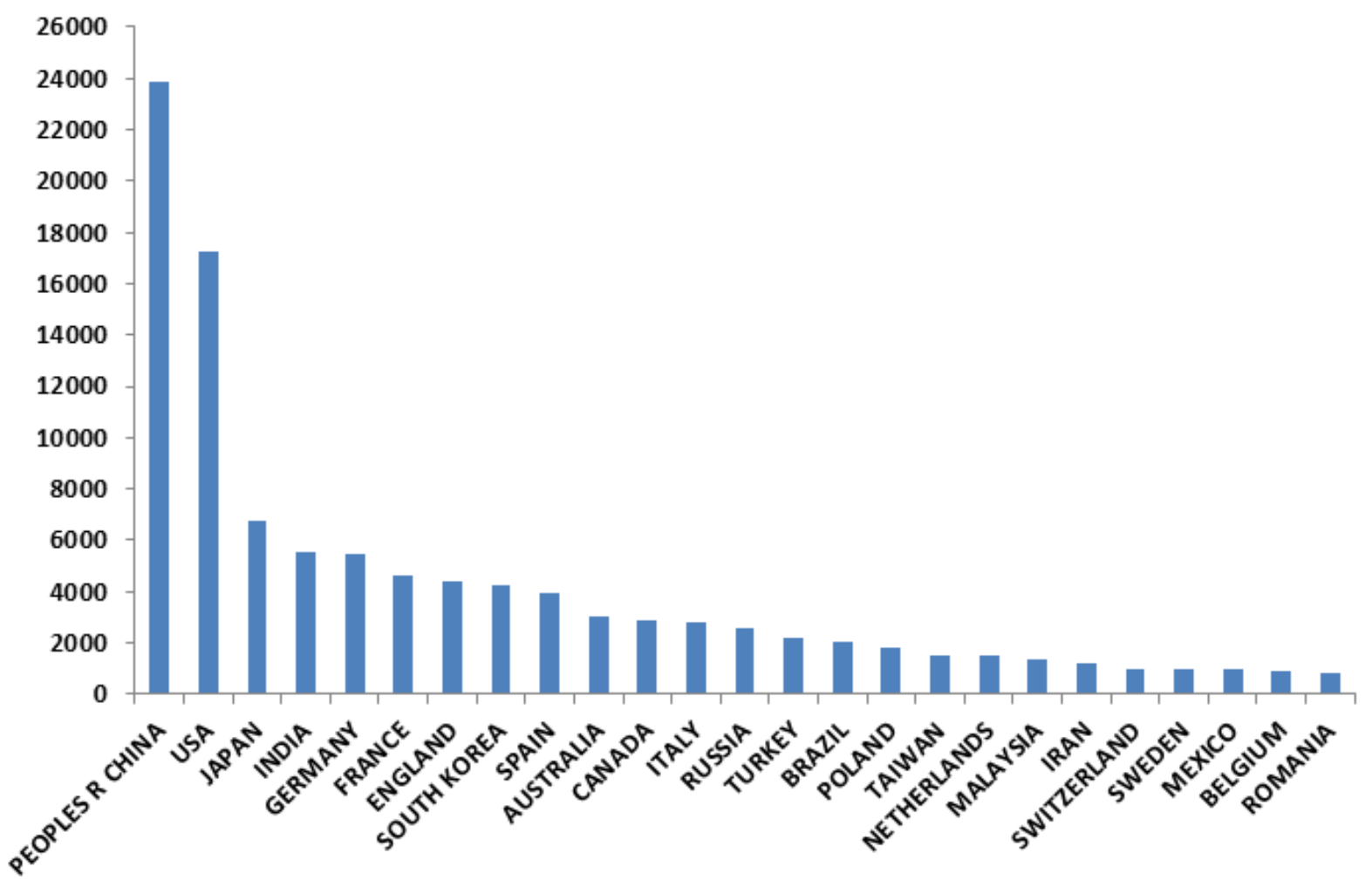

Fonte: Plataforma Web of Science, 2020.

Percebe-se que a China e os Estados Unidos, foram os países mais produtivos em relação ao tema, contribuindo para o crescimento da pesquisa, além do surgimento de novas tecnologias. A China, os Estados Unidos e o Japão produziram 23.871, 17.265 e 6.778 publicações cada, respectivamente.

Quando analisamos a China, por exemplo, fica evidente o empenho e preocupação do mesmo em desenvolver tecnologias capazes de solucionar problemas relacionados com o meio ambiente, com o intuito de reduzir não só a quantidade de resíduos sólidos que são gerados diariamente, como também a emissão de $\mathrm{CO}_{2}$, além da produção de bioenergia

A China está passando por uma urbanização maciça, a população total aumentou de 962,6 milhões em 1978 para 1375,6 milhões no final de 2005. Enquanto isso, a taxa de urbanização do país aumentou de 17,4 para 41,8\%, resultando em mais de 150 milhões de toneladas de RSU a cada ano e a geração de RSU está aumentando a uma taxa anual de 8 a 10\% (Cheng, et al., 2007). Além disso, a China se tornou o maior consumidor global de energia em 2011 e é o segundo maior consumidor mundial de petróleo, atrás dos Estados Unidos (IEA, 2015). 
Research, Society and Development, v. 9, n. 7, e144973827, 2020

(CC BY 4.0) | ISSN 2525-3409 | DOI: http://dx.doi.org/10.33448/rsd-v9i7.3827

Devido às características dos materiais pirolíticos e aos efeitos de fatores físicos e geométricos (características dos reatores), o estudo desse tema envolve diversas disciplinas. As 10 principais áreas de pesquisas relacionadas ao tema "Pyrolysis" de acordo com o número de publicações, podem ser vistas na Tabela 1.

Tabela 1. Áreas do conhecimento em que se concentram as pesquisas sobre o tema "Pyrolysis".

\begin{tabular}{cc}
\hline ÁREAS TEMÁTICAS & N DE PUBLICAÇÕES \\
\hline CHEMISTRY & 37.609 \\
ENGINEERING & 25.674 \\
ENERGY \& FUELS & 23.489 \\
MATERIALS SCIENC & 12.078 \\
PHYSICS & 7.498 \\
SCIENCE \& TECHNOLOGY - OTHER TOPIC & 7.073 \\
ENVIRONMENTAL SCIENCES \& ECOLOGY & 5.228 \\
THERMODYNAMICS & 3.990 \\
AGRICULTURE & 3.958 \\
\hline
\end{tabular}

Fonte: Plataforma Web of Science, 2020.

Conforme mostrado na Tabela 1, às áreas de pesquisas com maiores números de publicações se concentraram na área da chemistry, engineering, energy \& fuels e materials scienc, com 37.609, 31.818, 25.674 e 23.489 publicações cada, respectivamente, totalizando 118.590 publicações.

Além das principais áreas de pesquisas, também foi possível realizar a classificação das publicações quanto ao tipo de documentos. Na Tabela 2 podem ser observados os tipos de documentos referentes às publicações encontradas com o tema "Pyrolysis". 
Research, Society and Development, v. 9, n. 7, e144973827, 2020

(CC BY 4.0) | ISSN 2525-3409 | DOI: http://dx.doi.org/10.33448/rsd-v9i7.3827

Tabela 2. Classificação das publicações quanto ao tipo.

\begin{tabular}{cc}
\hline TIPO DE PUBLICAÇÃO & N DE PUBLICAÇÕES \\
\hline ARTICLE & 88.207 \\
\hline PROCEEDINGS PAPER & 13.694 \\
REVIEW & 2.714 \\
MEETING ABSTRACT & 2.101 \\
NOTE & 893 \\
LETTER & 405 \\
EARLY ACCESS & 372 \\
EDITORIAL MATERIAL & 164 \\
CORRECTION & 85 \\
\hline NEWS ITEM & 34 \\
\hline
\end{tabular}

Fonte: Plataforma Web of Science, 2020.

É possível constatar a preferência por parte dos autores na hora de expor os resultados de suas pesquisas. A maioria das publicações encontradas foram artigos, correspondendo a $87,02 \%$ do total das publicações, seguidos por trabalhos em congressos $(13,07 \%)$ e análises $(2,66 \%)$.

Já com o objetivo de identificar as publicações mais influentes na área da pirólise, foram selecionadas as 10 publicações mais citadas. A Tabela 3 exibe o título da publicação, o(s) autor(s) e o respectivo número de citações. 
Tabela 3. Publicações mais citadas com o tópico "Pyrolysis".

\begin{tabular}{|c|c|c|c|}
\hline TÍTILO & AUTORES & ANO & CITAÇÕES \\
\hline $\begin{array}{l}\text { Synthesis and characterization of nearly monodisperse } \\
C d E(E=S, S E, T E) \text { semiconductor nanocrystallites }\end{array}$ & Murray et al. & 1993 & 7220 \\
\hline $\begin{array}{l}\text { Synthesis of transportation fuels from biomass: } \\
\text { Chemistry, catalysts, and engineering }\end{array}$ & Huber et al. & 2006 & 4703 \\
\hline Lithium batteries and cathode materials & Whittingham & 2004 & 3709 \\
\hline Biodiesel production: a review & Ma e Hanna & 1999 & 3337 \\
\hline $\begin{array}{l}\text { Pyrolysis of wood/biomass for bio-oil: A critical } \\
\text { review }\end{array}$ & Mohan et al. & 2006 & 3009 \\
\hline $\begin{array}{l}\text { Characteristics of hemicellulose, cellulose and lignin } \\
\text { pyrolysis }\end{array}$ & Yang et al. & 2007 & 2807 \\
\hline $\begin{array}{l}\text { The Catalytic Valorization of Lignin for the Production of } \\
\qquad \text { Renewable Chemicals }\end{array}$ & Zakzeski et al. & 2010 & 2133 \\
\hline Overview of applications of biomass fast pyrolysis oil & $\begin{array}{l}\text { Czernik e } \\
\text { Bridgwater }\end{array}$ & 2004 & 1714 \\
\hline Electrochemical technologies in wastewater treatment & Chen & 2004 & 1671 \\
\hline $\begin{array}{c}\text { Intrinsic n-type versus p-type doping asymmetry and } \\
\text { the defect physics of } \mathrm{ZnO}\end{array}$ & Zhang et al. & 2001 & 1511 \\
\hline
\end{tabular}

Fonte: Plataforma Web of Science, 2020.

A publicação com o maior número de citações foi publicada em 1993, com o título "Synthesis and characterization of nearly monodisperse $C d E(E=S, S e, T e)$ semiconductor nanocrystallites", na revista Journal of the American Chemical Society, volume 115, edição 19, pelos autores Murray, C.B., Norris, D.J., Bawendi, M.G,onde foi apresentada uma rota simples para a produção de nanocristalitos semicondutores $\mathrm{CdE}(\mathrm{E}=\mathrm{S}, \mathrm{Se}, \mathrm{Te})$ de alta qualidade. A síntese foi baseada na pirólise de reagentes organometálicos por injeção em um solvente de coordenação a quente. Além disso, esse trabalho está classificado na área de pesquisa da chemistry (Tabela 1), evidenciando o maior número de publicação nessa área de pesquisa. 


\subsection{Características das publicações com o Tópico "Pyrolysis", "Carton Packages" e}

\section{"Tetra Pak"}

A partir do termo "Pyrolysis" foi realizado um refinamento utilizando os termos "Carton Packages" e "Tetra Pak" no banco de dados da Web of Science, sendo encontradas 23 publicações. A primeira publicação ocorreu no ano de 2009 com o tema "Pyrolysis of the Tetra Pak”, na revista Waste Management, volume 29, $11^{\circ}$ edição, pelos autores Korkmaz, A., Yanik, J., Brebu, M., Vasile, C.

Ao compilar a evolução das publicações por ano relacionadas ao tema adicionando os termos "Carton Packages" e "Tetra Pak" no refinamento das buscas (Figura 4), percebe-se que os estudos sobre a recuperação das embalagens cartonadas são recentes.

Figura 4. Projeção do número de publicações por anual sobre o tema "Pyrolysis" adicionando os termos "Carton Packages" e "Tetra Pak".

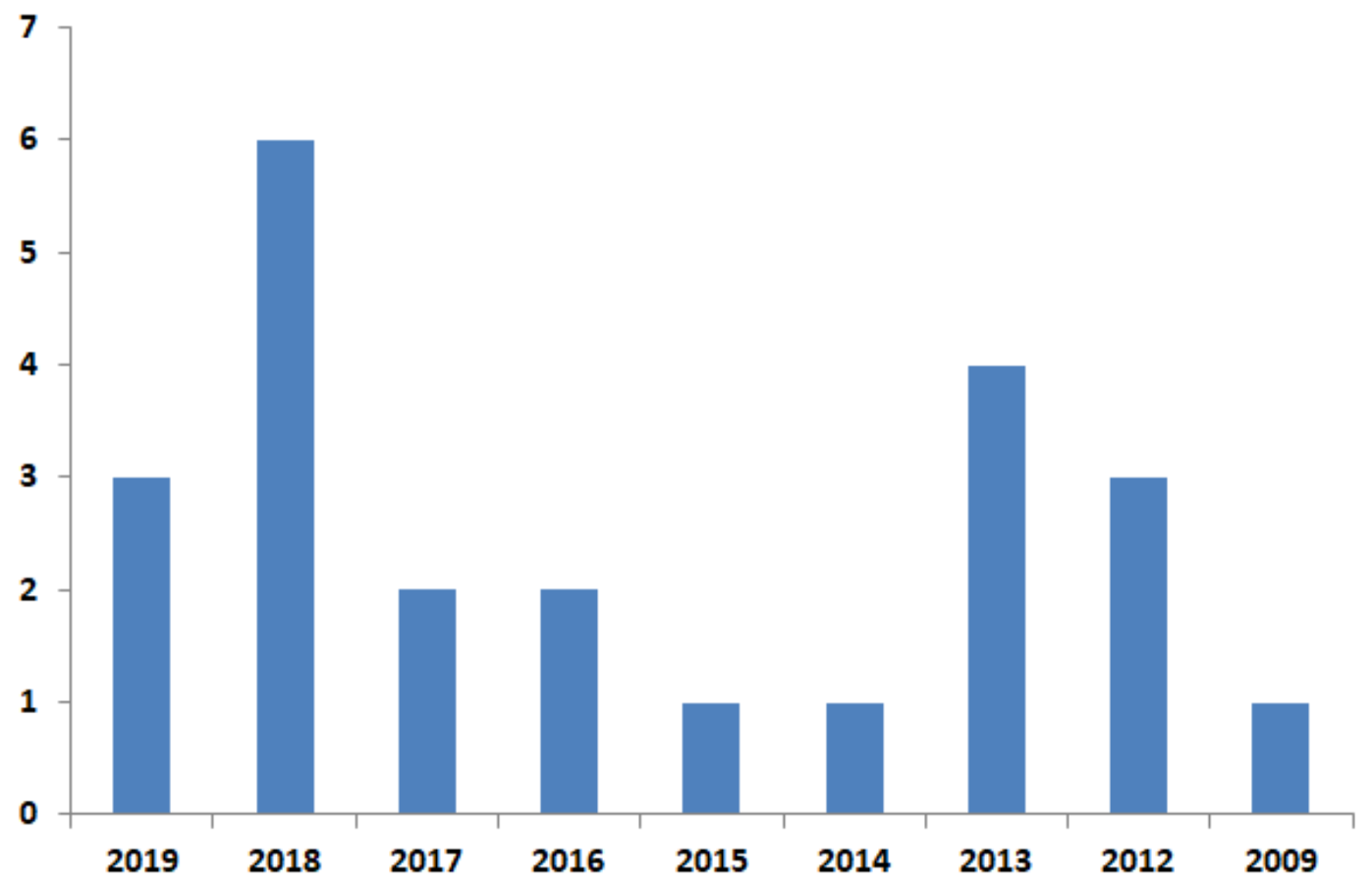

Fonte: Plataforma Web of Science, 2020.

O que sugere uma evidente preocupação em desenvolver pesquisas e tecnologias capazes de recuperar resíduos cartonados. A reciclagem de embalagens cartonadas cresce a cada ano, e é indicada como uma alternativa para diminuir o impacto ambiental, devido ao descarte inadequado dos resíduos (difícil degradação dos materiais constituintes). Além de possibilitar a recuperação de materiais com altos valores agregados. 
No entanto, os processos de reciclagem das embalagens cartonadas são complexos, devido principalmente à dificuldade de separação do alumínio do polietileno. $\mathrm{O}$ exposto acima enfatiza a necessidade de pesquisas com objetivo de contornar as dificuldades encontradas durante o processo, possibilitando a recuperação/reciclagem do maior número possível de embalagens, já que de acordo com dados da Tetra Pak, empresa produtora de embalagens cartonadas, esta foi responsável pela venda de mais de 189 bilhões de embalagens longa vida distribuída em mais de 160 países em 2018 (Tetra Pak, 2020).

Dos países que mais realizaram publicações, utilizando os termos "Carton Packages" e "Tetra Pak", pode se observar que o Brasil foi o país que se destacou em relação à recuperação de embalagens cartonadas via pirólise (Figura 5), evidenciando a preocupação/contribuição do mesmo com o crescimento da pesquisa e o surgimento de novas tecnologias.

Figura 5. Projeção da quantidade de publicação por países sobre o tema "Pyrolysis" adicionando os termos "Carton Packages" e "Tetra Pak".

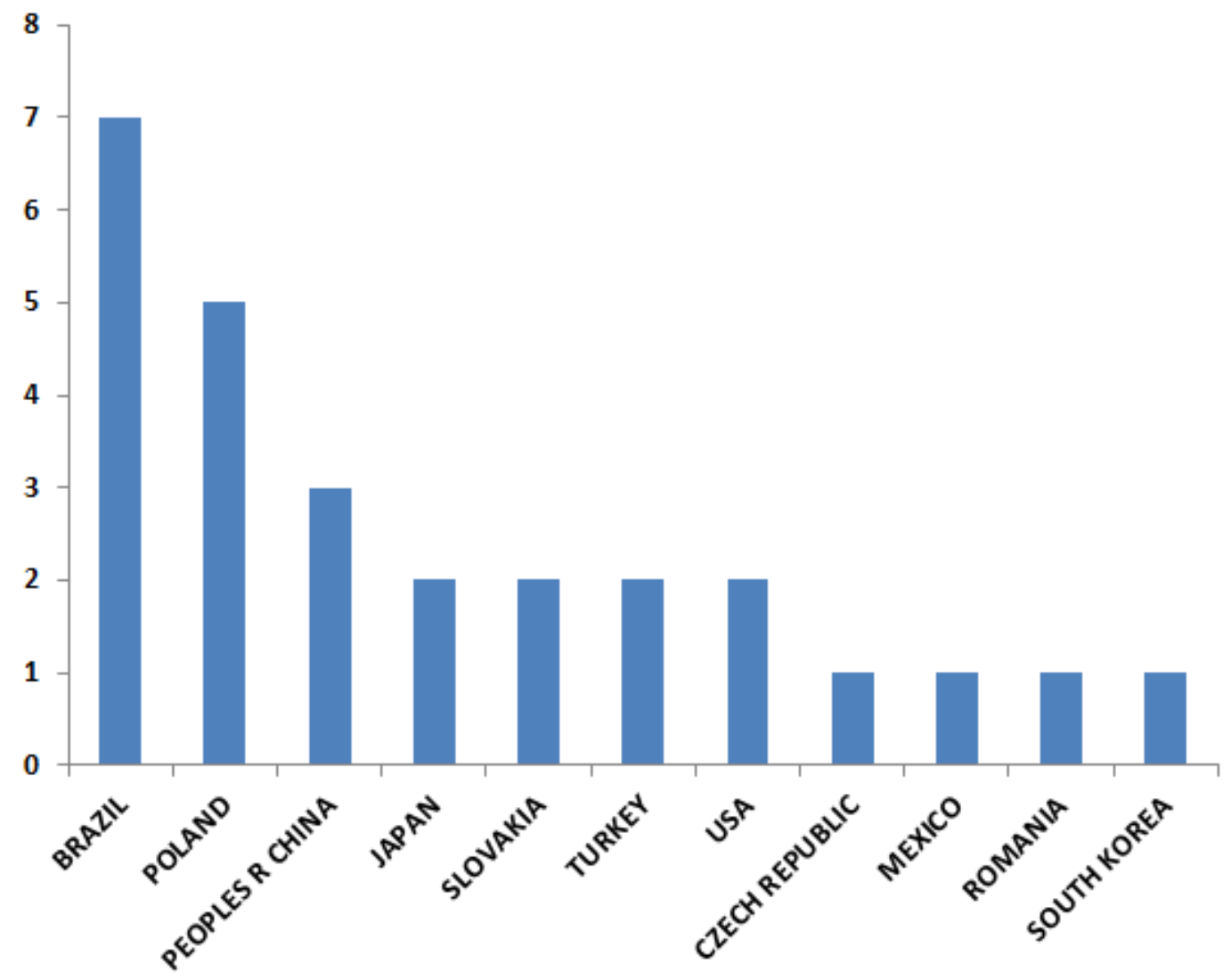

Fonte: Plataforma Web of Science, 2020. 
Research, Society and Development, v. 9, n. 7, e144973827, 2020

(CC BY 4.0) | ISSN 2525-3409 | DOI: http://dx.doi.org/10.33448/rsd-v9i7.3827

Com o auxilio do CiteSpace, foi possível a criação da rede de coautoria de países, com o intuito de verificação quantitativa das publicações e a da cooperação entre os principais países (Figura 6). Os tamanhos dos rótulos e dos círculos foram determinados pelo número de publicações em cada país, e a espessura das linhas entre dois nós representa a força da cooperação entre os países (Yang, et al., 2019).

Figura 6. Rede de coautoria de países relacionada ao tema "Pyrolysis" adicionando os termos "Carton Packages" e "Tetra Pak".

MEXICO

\section{BRAZIL}

POLAND SLOVAKIA

USA

\section{PEOPLES R CHINA}

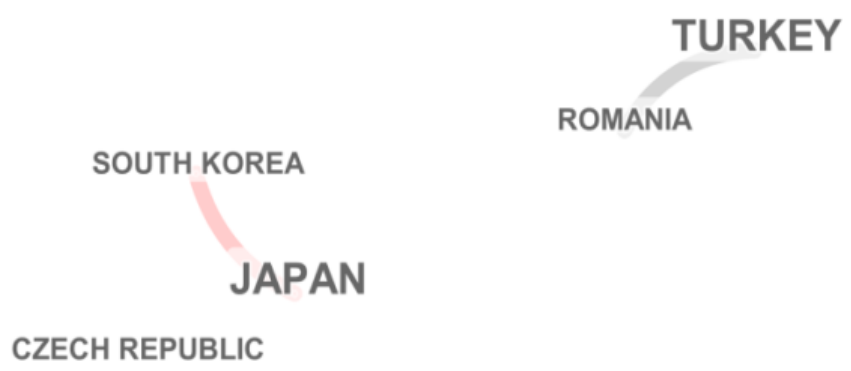

Fonte: Software CiteSpace, 2020.

É possível observar que 11 países estão contribuindo para a pesquisa e o desenvolvimento dos processos de reciclagem das embalagens cartonadas (Figura 6). O Brasil foi o país que se destacou com o maior número de publicações sobre o tema ( 7 no total) e logo após em segundo e terceiro lugar, respectivamente, à Polônia e à China com 5 e 3 publicações, respectivamente.

A Figura 6 complementou de forma ilustrativa os dados exibidos na Figura 5, o que permitiu a visualização dos relacionamentos cooperativos entre os países. As linhas entre os países indicam que existe um relacionamento cooperativo nas pesquisas sobre o tema discutido, como é o caso entre o Brasil e os Estados Unidos, Turquia e Romênia, Japão e Coréia do Sul. 
Research, Society and Development, v. 9, n. 7, e144973827, 2020

(CC BY 4.0) | ISSN 2525-3409 | DOI: http://dx.doi.org/10.33448/rsd-v9i7.3827

As principais áreas de pesquisas relacionadas ao tema recuperação de embalagens cartonadas através da pirólise podem ser vistas na Tabela 4. Sendo classificadas de acordo com o número de publicações.

Tabela 4. Áreas do conhecimento em que se concentram as pesquisas relacionadas ao tema "Pyrolysis" adicionando os termos "Carton Packages" e "Tetra Pak".

\begin{tabular}{|c|c|}
\hline ÁREAS DE PESQUISAS & $\mathbf{N}^{\circ}$ DE PUBLICAÇÕES \\
\hline ENGINEERING CHEMICAL & 10 \\
\hline ENERGY \& FUELS & 7 \\
\hline ENVIRONMENTAL SCIENCES & 7 \\
\hline ENGINEERING ENVIRONMENTAL & 5 \\
\hline AUTOMATION \& CONTROL SYSTEMS & 1 \\
\hline CHEMISTRY ANALYTICAL & 1 \\
\hline CHEMISTRY MULTIDISCIPLINARY & 1 \\
\hline CHEMISTRY, PHYSICAL & 1 \\
\hline COMPUTER SCIENCE, & 1 \\
\hline INTERDISCIPLINARY APPLICATIONS & \\
\hline EDUCATION, SCIENTIFIC DISCIPLINES & 1 \\
\hline
\end{tabular}

Fonte: Plataforma Web of Science, 2020.

As três principais áreas da pesquisa que se destacaram em relação aos maiores números de publicações foram engineering chemical, energy \& fuels e environmental sciences, com 10, 7 e 7 publicações cada.

Com a utilização do software CiteSpace, foi criada uma rede com as principais áreas de pesquisas (Figura 7). 
Research, Society and Development, v. 9, n. 7, e144973827, 2020

(CC BY 4.0) | ISSN 2525-3409 | DOI: http://dx.doi.org/10.33448/rsd-v9i7.3827

Figura 7. Rede com as principais áreas de pesquisa relacionada ao tema "Pyrolysis" adicionando os termos "Carton Packages" e "Tetra Pak".

AUTOMATION \& CONTROL SYSTEMS

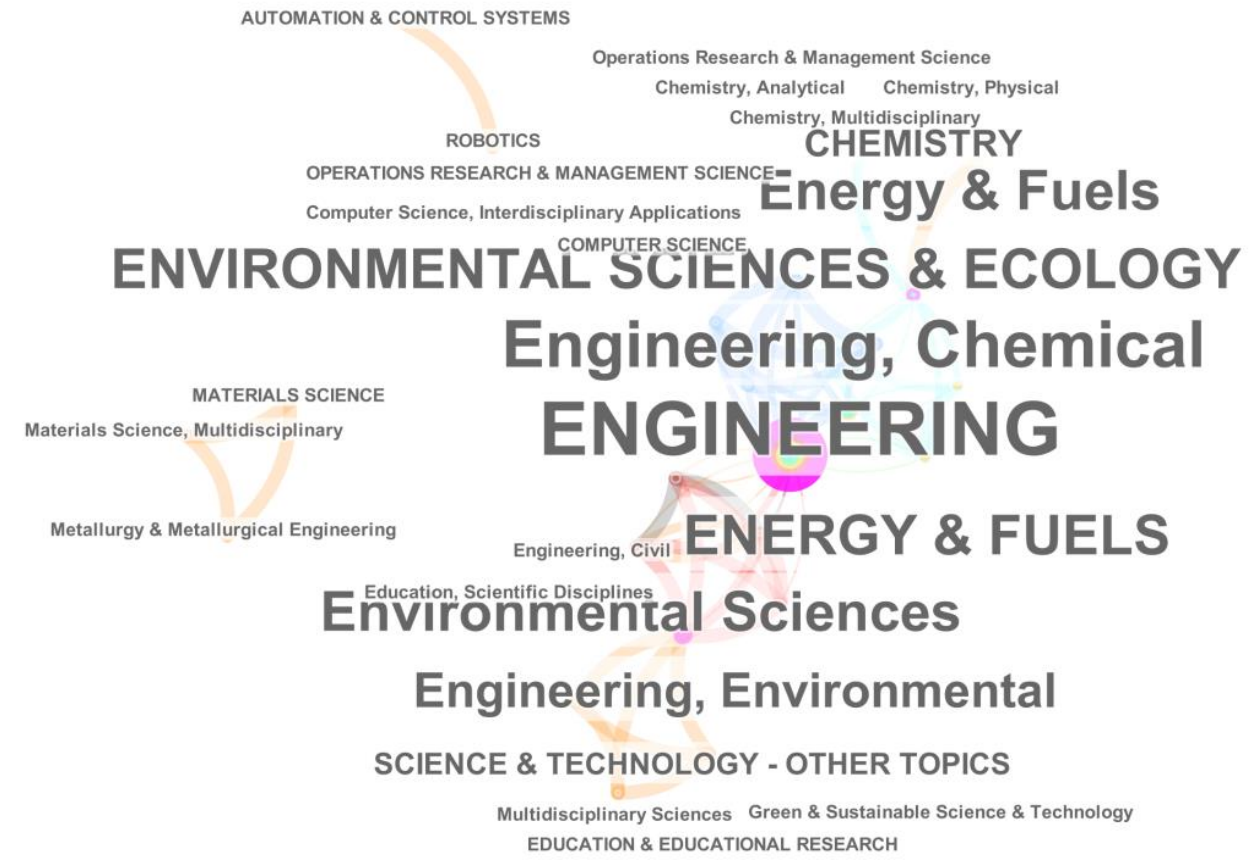

Fonte: Software CiteSpace, 2020.

Os tamanhos das palavras foram determinados pelo número de publicações em cada área. Como pode ser visto na Tabela 4, as áreas que se destacaram em relação ao número de publicações em ordem decrescente foram engineering; engineering, chemical; energy \& fuels e environmenal sciences \& ecology.

Foi realizada uma análise dos tipos de documentos referentes às publicações encontradas com o tema recuperação de embalagens cartonadas através da pirólise (Tabela 5).

Tabela 5. Classificação das publicações quanto ao tipo.

\begin{tabular}{cc}
\hline TIPO DE PUBLICAÇÃO & $\mathbf{N}^{\circ}$ DE PUBLICAÇÕ OES \\
\hline ARTICLE & 17 \\
PROCEEDINGS PAPER & 8 \\
\hline
\end{tabular}

Fonte: Plataforma Web of Science, 2020.

A análise revelou a preferência dos autores em publicar suas pesquisas em artigos, sendo duas vezes maiores os números de publicações em artigos do que em congressos. 
Research, Society and Development, v. 9, n. 7, e144973827, 2020

(CC BY 4.0) | ISSN 2525-3409 | DOI: http://dx.doi.org/10.33448/rsd-v9i7.3827

Uma rede de coautoria foi construída, permitindo identificar os autores mais produtivos e os mais renomados grupos de pesquisa com a utilização do software VOSviewer (Figura 8). A análise de coautoria identifica os padrões subjacentes de colaboração entre os pesquisadores que trabalham no campo (Jiang, et al., 2019).

Figura 8. Rede de coautoria relacionada ao tema "Pyrolysis" adicionando os termos "Carton

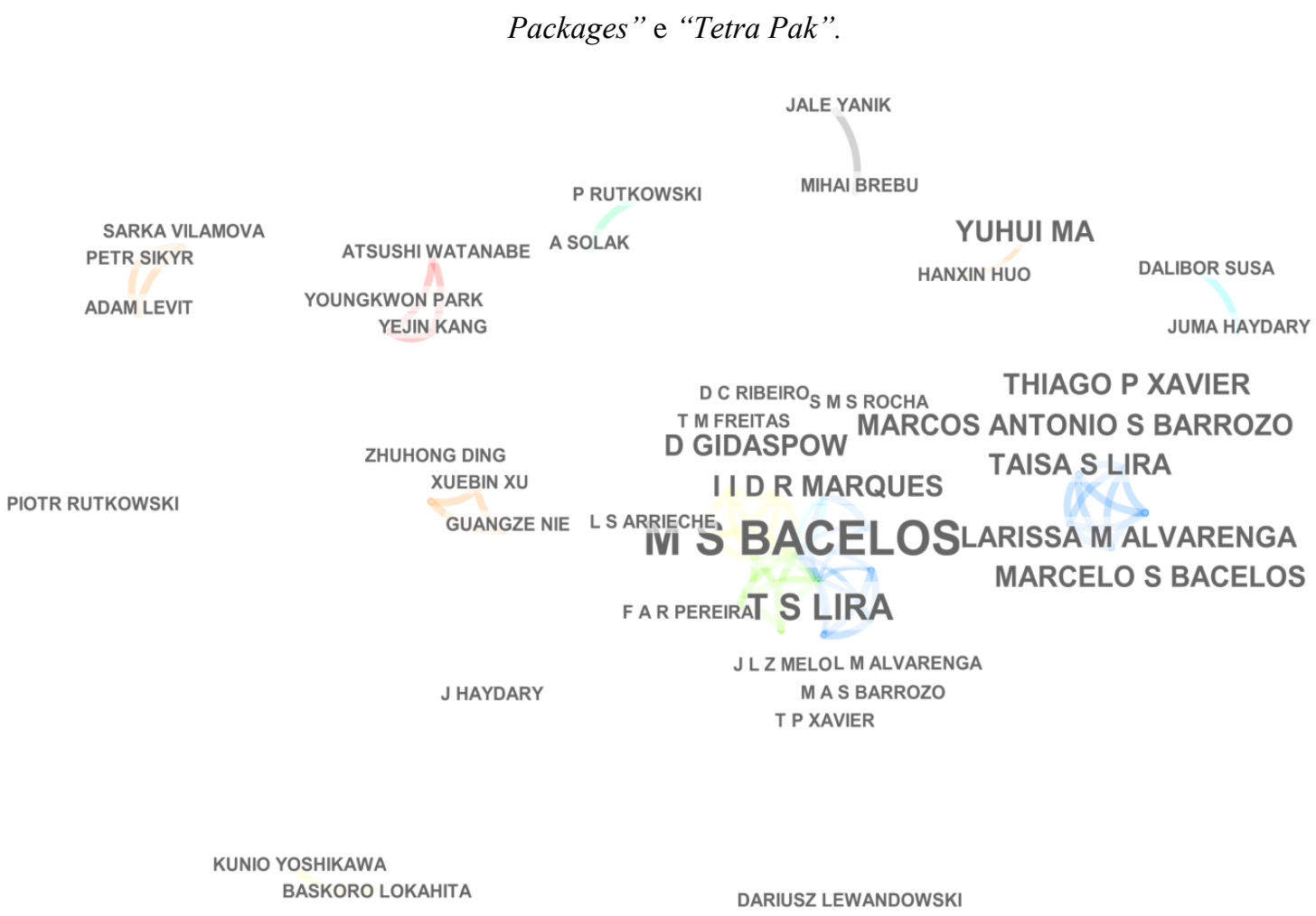

Fonte: Software CiteSpace, 2020.

Os autores com maior peso, em termos de citações e publicações, foram representados como nós maiores (Yang, et al., 2019). Cada nó representa um autor e as linhas e distâncias refletem a relação entre eles. A distância entre dois nós indica a intensidade da relação, o que significa que, quando dois nós estão mais próximos, eles tendem a ter uma relação forte.

A figura 8 teve como destaque o pesquisador Bacelos, M.S, possuindo 5 publicações, ou seja, o maior número de publicações relacionado ao tema, e logo após em segundo lugar a Lira, T.S com um total de 3 publicações.

Observa-se que os pesquisadores foram separados em grupos (Clusters), classificados de acordo com a intensidade da ocorrência de coautoria. Os pesquisadores do mesmo cluster têm maior poder de colaboração em pesquisa e compartilham publicações mais semelhantes com os pesquisadores desse cluster específico (Ang, et al., 2019). 
Os autores foram divididos em grupos, representando suas redes de pesquisas, como por exemplo, o grupo de pesquisa formado Bacelos, M.S., Lira, T.S., Marques, I.I.D.R, Rocha, S.M.S, Arrieche, L.S., Freitas, T.M., Gidaspow, D., Ribeiro, D.C., Alvarenga, L.M., Barrozo, M.A.S., Xavier, T.P., Melo, J.L.Z., Pereira, F.A.R.

A análise de citações é uma maneira eficaz de medir o impacto e a qualidade de uma publicação, observando o número de vezes que uma publicação foi citada por outro trabalho e identificando as publicações mais importantes em um campo de pesquisa (Yang, et al., 2019). Dessa maneira, foram realizadas análises de cocitação de organização (Figura 9), de referências (Figura 10) e periódicos (Figura 11).

Com a utilização do software VOSviewer, foi possível criar uma rede de cocitação de organização (Figura 9). Obtendo 24 organizações que realizaram pesquisas sobre o tema recuperação de embalagens cartonadas através da pirólise.

De acordo com a rede de cocitação de organização (Figura 9), a mesma é composta por 4 diferentes cluters. A figura 9 está centrada na Ege University e no Institute of Macromolecular Chemistry Petru Poni, devido ao grande número de citações que ambas possuem (52 citações cada), dessa forma, se conectando as outras principais organizações dos demais cluters.

Figura 9. Rede de citação de organização relacionada ao tema "Pyrolysis" adicionando os termos “Carton Packages" e "Tetra Pak”.

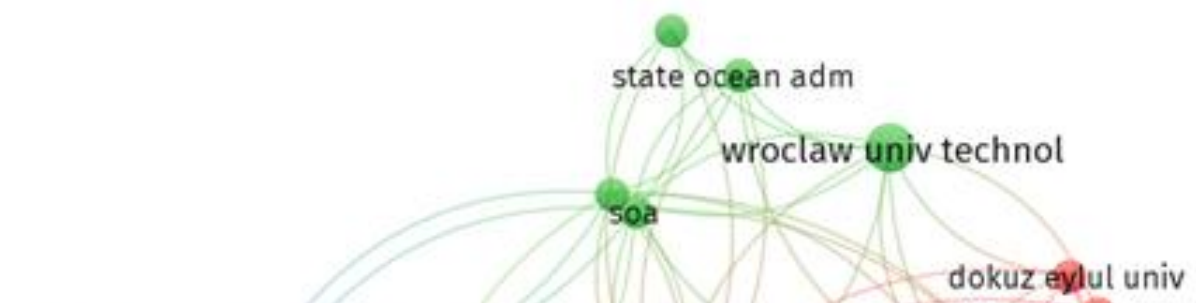

univ fed espirito santo

uni fed uberlandia uaem unam ege univ stovak univ technol bratislava

nanjing tech univ 
Dentre as organizações exibidas, a Universidade Federal do Espírito Santo foi a que teve o maior número de documentos publicados, com um total de 7 publicações sobre o tema e em terceiro lugar em número de citações (41 citações) e em quarto lugar a Universidade Federal de Uberlândia com um total de 25 citações e 3 documentos pulicados.

Uma rede de cocitação de referência foi criada no VOSviewer (Figura 10). Para a criação da rede de cocitação de referência, foi definido como sendo 4 o número mínimo de citações, com o intuito de selecionar as publicações com maior importância. Das 506 publicações analisadas, apenas 10 atingem o limite.

Figura 10. Rede de cocitações de referências relacionada ao tema "Pyrolysis" adicionando os termos "Carton Packages" e "Tetra Pak".

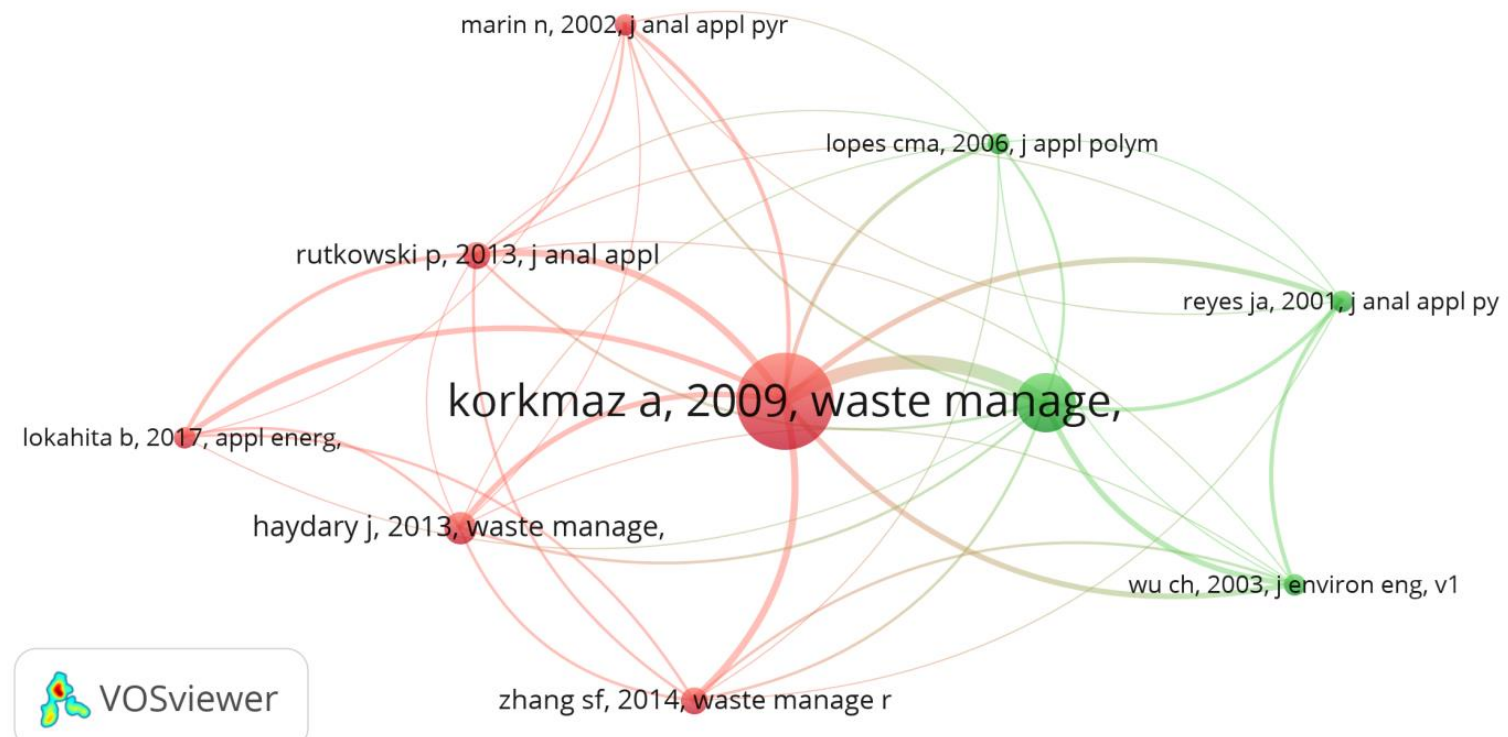

Fonte: Software VOSviewer, 2020.

Cocitação de referência significa que duas referências foram citadas por artigos diferentes ao mesmo tempo (Liu, et al., 2019). Os nós representam diferentes referências cocitadas, onde nós maiores indicam um maior número de cocitação.

Foram exibidos os artigos mais influentes sobre o tema (Figura 10), sendo formada por 2 cluters, totalizando 10 itens. O cluster principal (vermelho) está centrado no artigo Pyrolysis of the Tetra Pak (Korkmaz, et al., 2009), que foi o artigo com o maior número de citações. Onde, realizaram a pirólise do material de embalagens Tetra Pak, a fim de obter produtos com possíveis aplicações valiosas, contribuindo significativamente com as pesquisas. 
A cocitação de periódicos foi realizada através do CiteSpace. Uma linha que liga dois periódicos significa que esses dois periódicos foram citados na mesma publicação, e a espessura da linha de conexão representa a força da cocitação entre esses dois periódicos (Liu, et al., 2019).

Para a criação da rede de cocitação de periódicos (Figura 11), foram analisados 204 periódicos relacionados com o tema. A Figura 11 exibe os agrupamentos e suas relações por meio de linhas de conexão.

Figura 11. Rede dos principais periódicos relacionada ao tema "Pyrolysis" adicionando os termos “Carton Packages" e "Tetra Pak”.

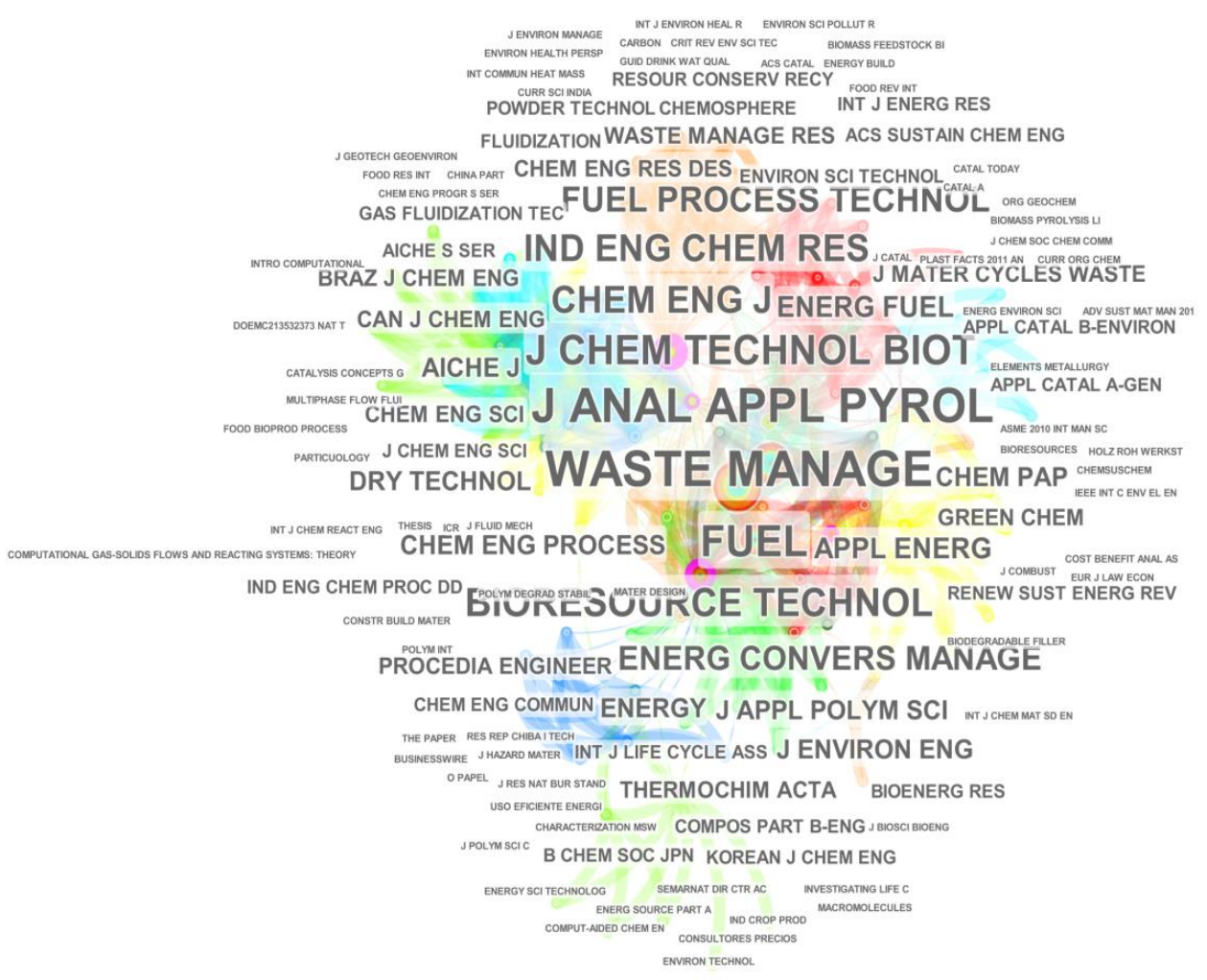

Fonte: Software CiteSpace, 2020.

A Figura 11 possui diversos clusters. O cluster principal está centrado no periódico Journal of Analytical and Applied Pyrolysis (J. ANAL. APPL. PYROL.), possuindo o maior número de citações, o que significa que esse foi o periódico mais citado em outros periódicos, como pode ser visto através do tamanho da fonte, logo após temos o Fuel, Waste Manage, Industrial \& Engineering Chemistry Research e a Chemical Engineering and Processing, respectivamente. Analisando a força de cocitação, a linha que liga o Journal of Analytical and Applied Pyrolysis (J. ANAL. APPL. PYROL.) ao Fuel foi a mais espessa indicando que ambos foram cocitados com mais frequência. 
Foram realizadas análises para gerar a rede de coocorrência de palavras-chave utilizando o VOSViewer (Figuras 12 e 13). Cada palavra-chave foi representada por um círculo em que o tamanho indica o número de ocorrências de uma palavra-chave específica (Ang, et al., 2019).

Para a criação da rede de coocorrência de palavras-chave, foram definido como sendo 2 o número mínimo de ocorrências de uma palavras-chave mais relevantes. Das 130 palavraschave analisadas, apenas 36 atingem o limite.

Figura 12. Rede de coocorrência de palavras-chave relacionada ao tema "Pyrolysis" adicionando os termos "Carton Packages" e "Tetra Pak".

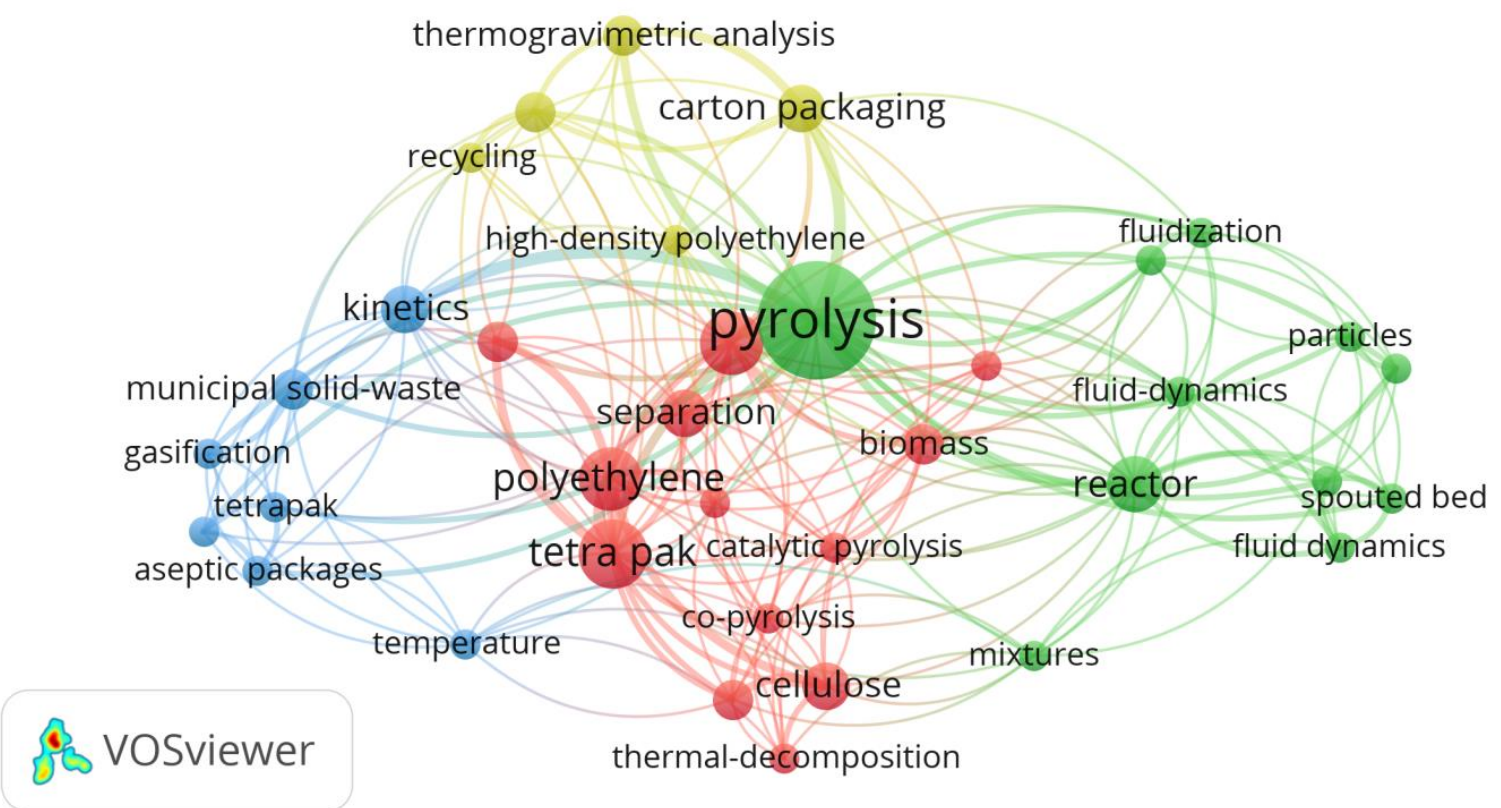

Fonte: Software VOSviewer, 2020.

Análises das redes de coocorrência de palavras-chave tiveram como função auxiliar no reconhecimento dos principais tópicos e tendências de pesquisa na área. $\mathrm{Na}$ análise de coocorrência, a força do link entre as palavras-chave do autor indica o número de publicações nas quais duas palavras-chave ocorrem juntas (Khudzari, et al., 2018).

A Figura 12 possui 4 cluters. O cluster principal (verde) está centrado na palavrachave "pyrolysis" que possui o maior número de ocorrência entre todas (16 no total), e que se conecta as principais palavras-chave dos outros clusters, que foram os termos estudados com maior frequência, incluindo as palavras polyethylene, Tetra Pak, waste e reactor. 
Research, Society and Development, v. 9, n. 7, e144973827, 2020

(CC BY 4.0) | ISSN 2525-3409 | DOI: http://dx.doi.org/10.33448/rsd-v9i7.3827

Outa forma de analise de coocorrência de palavras-chave foi através de um mapa de densidade (Figura 13), destacando a ocorrência de palavras-chave através de cores. Cores frias (azul e verde) foram usadas para palavras-chave com menos frequências e cores quentes (amarelo, laranja e vermelho) para palavras-chave usadas com mais frequência.

Figura 13. Mapa de densidade de coocorrência de palavras-chave relacionada ao tema "Pyrolysis" adicionando os termos "Carton Packages" e "Tetra Pak".

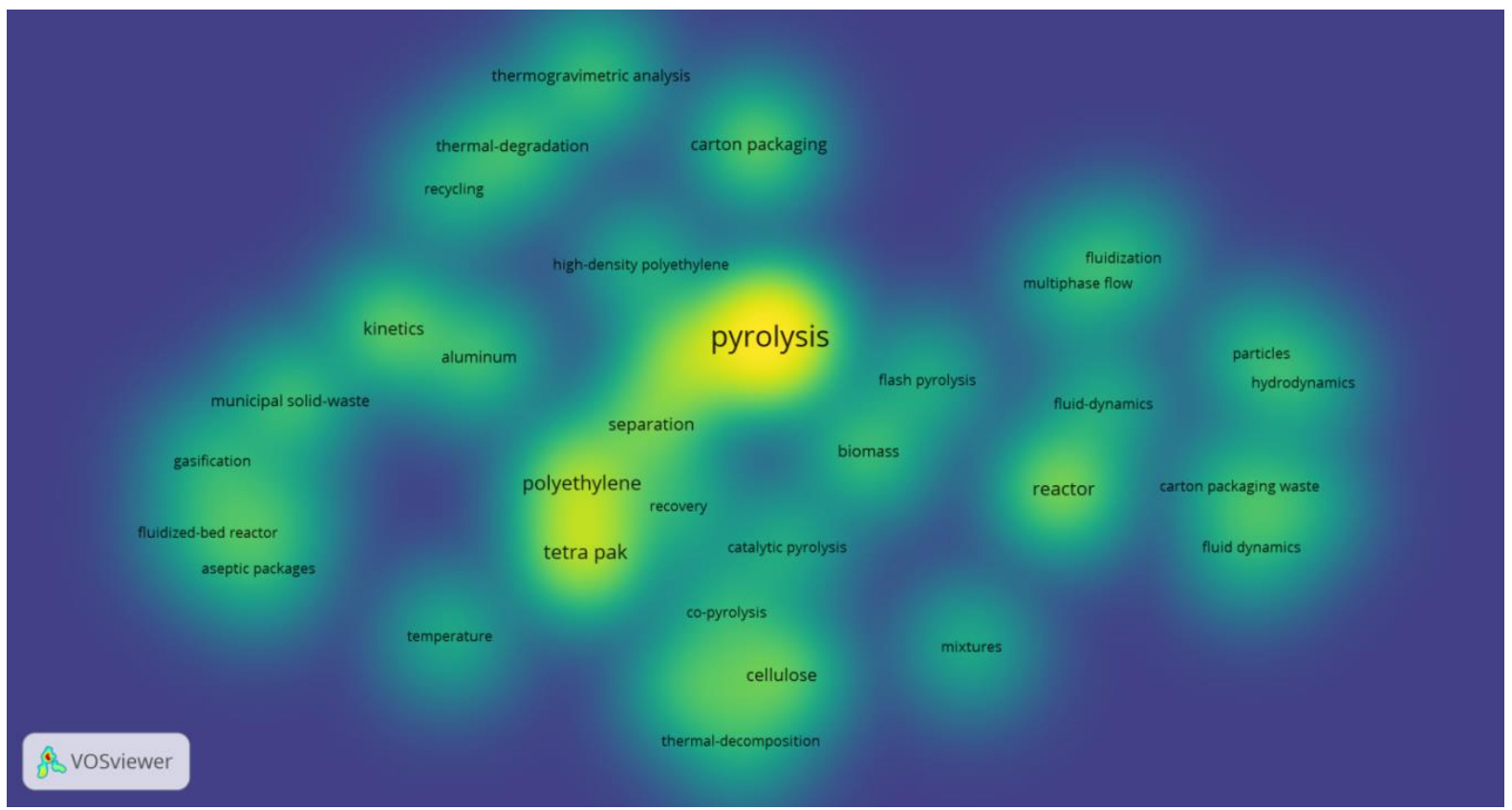

Fonte: Software VOSviewer, 2020.

Dentre as 23 publicações sobre o tópico, foram selecionados os 10 artigos mais citados até o ano de 2019. 
Research, Society and Development, v. 9, n. 7, e144973827, 2020

(CC BY 4.0) | ISSN 2525-3409 | DOI: http://dx.doi.org/10.33448/rsd-v9i7.3827

Tabela 6. Artigos mais citados encontrados na base de dados da Web of Science utilizando os termos "Carton Packages" e "Tetra Pak".

\begin{tabular}{|c|c|c|c|}
\hline TÍTULO & AUTORES & ANO & CITAÇÕES \\
\hline Pyrolysis of the tetra pak & Korkmaz et al. & 2009 & 52 \\
\hline $\begin{array}{l}\text { Pyrolysis of aseptic packages (tetra pak) in a } \\
\text { laboratory screw type reactor and secondary } \\
\text { thermal/catalytic tar decomposition }\end{array}$ & Haydary et al. & 2013 & 18 \\
\hline $\begin{array}{l}\text { Energy and resource recovery from Tetra Pak } \\
\text { waste using hydrothermal treatment }\end{array}$ & Lokahita et al. & 2017 & 15 \\
\hline $\begin{array}{l}\text { Determination of activation energy of pyrolysis } \\
\text { of carton packaging wastes and its pure components } \\
\text { using thermogravimetry }\end{array}$ & Alvarenga et al. & 2016 & 9 \\
\hline $\begin{array}{l}\text { CFD modeling of conical spouted beds for } \\
\text { processing LDPE/Al composite }\end{array}$ & Melo et al. & 2016 & 8 \\
\hline $\begin{array}{c}\text { Bio-oil production by fast pyrolysis of } \\
\text { cellulose/polyethylene mixtures in the presence of metal } \\
\text { chloride }\end{array}$ & $\begin{array}{c}\text { Solak e } \\
\text { Rutkowski }\end{array}$ & 2014 & 8 \\
\hline $\begin{array}{l}\text { Development of a process using waste } \\
\text { vegetable oil for separation of aluminum and } \\
\text { polyethylene from Tetra Pak }\end{array}$ & $\begin{array}{l}\text { Rodríguez- } \\
\text { Gómez et al. }\end{array}$ & 2015 & 7 \\
\hline $\begin{array}{l}\text { Characteristics of bio-oil obtained by catalytic } \\
\text { pyrolysis of beverage carton packaging waste }\end{array}$ & Rutkowski & 2013 & 6 \\
\hline $\begin{array}{l}\text { Kinetics of thermal decomposition of aseptic } \\
\text { packages }\end{array}$ & Haydary e Susa & 2013 & 5 \\
\hline Changing Tetra Pak: from waste to resource & $\mathrm{Ma}$ & 2018 & 4 \\
\hline
\end{tabular}

Fonte: Plataforma Web of Science, 2020.

Korkmaz et al. (2009) realizaram a pirólise do material das embalagens Tetra Pak, a fim de obter produtos com possíveis aplicações valiosas. Para tal, realizaram a pirólise em atmosfera de nitrogênio usando um reator de pirólise (projeto de leito fixo de aço inoxidável). Foram utilizada amostras de aproximadamente $50 \mathrm{~g}$, o sistema foi aquecido a uma taxa de $5^{\circ} \mathrm{C} \cdot \mathrm{min}^{-1}$ até a temperatura desejada e mantida nessa temperatura por $1 \mathrm{~h}$. 
A pirólise dos resíduos foi investigada em diferentes temperaturas $\left(400-600{ }^{\circ} \mathrm{C}\right)$. A pirólise dos resíduos produziu gás e cera, além de resíduos de carbono e alumínio puro. $\mathrm{O}$ carvão obtido da pirólise foi adequado para uso como combustível sólido, devido ao seu alto valor calorífico e baixo teor de cinzas. O produto gasoso era formado principalmente pela degradação do papelão e continha uma alta proporção de óxidos de carbono. Os resultados do TGA (Análise Termogravimétrica) mostraram que a pirólise do material das embalagens Tetra Pak consistia em dois estágios distintos. A primeira etapa (abaixo de $400{ }^{\circ} \mathrm{C}$ ) foi contribuída pela reação de degradação primária do papelão. A degradação do polietileno foi significativa no segundo estágio. Com base nos resultados de TGA (Análise Termogravimétrica), foi realizada pirólise por etapas para obter o produto de cera com menos impureza, como compostos alcalinos da degradação da celulose.

Haydary et al. (2013) estudaram a pirólise de embalagens assépticas (embalagens Tetra Pak), usando um reator de fluxo do tipo parafuso e um reator catalítico secundário para o craqueamento do alcatrão. Os experimentos de pirólise foram realizados em escala laboratorial e em atmosfera de nitrogênio a temperaturas variando de $650{ }^{\circ} \mathrm{C} \mathrm{a} 850{ }^{\circ} \mathrm{C}$, com o objetivo de maximizar a quantidade do produto gasoso e reduzir o teor de alcatrão.

A folha de alumínio foi facilmente separada do produto sólido. A cor e a estrutura do alumínio mudaram com a temperatura acima de $750{ }^{\circ} \mathrm{C}$. A parte restante do produto sólido foi formada com baixo teor de enxofre e nitrogênio, combustível sólido com teor de cinzas em torno de $22 \%$ e valor calorífico de $15 \mathrm{MJ} / \mathrm{kg}$.

Dois tipos de catalisadores (dolomita e argila vermelha marcado com AFRC) foram usados para a decomposição catalítica. Ambos os tipos de catalisadores afetaram significativamente o teor de alcatrão e outros componentes nos gases pirolíticos. No processo usando dolomita como catalisador, a quantidade total de alcatrão foi reduzida e, a $850{ }^{\circ} \mathrm{C}$ foi produzido um rendimento não mensurável de alcatrão. No processo com o AFRC como catalisador, a fração orgânica do alcatrão foi muito menor do que nos outros dois processos. A seletividade da dolomita ao $\mathrm{CO}$ e $\mathrm{H}_{2}$ é maior que a da AFCR. No entanto, a capacidade geral do AFCR na remoção orgânica de alcatrão é melhor.

Lokahita et al. (2017) apresentaram um novo método de reciclagem de resíduos da Tetra Pak, usando um processo hidrotérmico, capaz de decompor papel e polietileno. O processo elimina o efeito adesivo do polietileno e depois separa o alumínio do papel. O processo hidrotérmico também degrada o papel em um material semelhante ao carvão, com alto valor calorífico, excelente como combustível sólido. Nove experimentos, que consistiam em três variações de temperatura e tempo, foram conduzidos neste estudo. As temperaturas da 
reação foram de 200,220 e $240{ }^{\circ} \mathrm{C}$, e os tempos de retenção foram de 0,30 e $60 \mathrm{~min}$. A investigação foi composta de duas partes: propriedades de combustíveis sólidos e recuperação de alumínio.

A investigação das características do produto provou que o tratamento hidrotérmico pode aumentar o teor de carbono do hidrocarboneto, quebrando as partes de papel do Tetra Brik (papel, polietileno e alumínio). A espectroscopia de energia dispersiva e as análises DTA (Análise Térmica Diferencial) mostraram que também foram formados compostos de alumínio e polietileno.

À medida que o teor de carbono aumentava o HHV (alto valor de aquecimento) também aumentava, enquanto o teor de cinzas diminuía de acordo. O HHV mais alto foi encontrado a uma temperatura operacional de $240{ }^{\circ} \mathrm{C}$ e tempo de espera de $60 \mathrm{~min}$. O HHV é importante porque indica a quantidade de energia no combustível. O tratamento hidrotérmico também diminuiu o conteúdo volátil e de cinzas, aumentando o teor fixo de carbono. $\mathrm{O}$ tratamento hidrotérmico também pode aumentar o HHV da biomassa da Tetra Brik em até 25,22 MJ/kg, o que é comparável a lignite e ao carvão. Além disso, o rendimento de alumínio do processo foi de até $37 \%$.

Alvarenga et al. (2016), a fim de contribuir para uma maior compreensão da cinética de reação da pirólise de embalagens cartonadas, analisaram dois tipos diferentes de modelos cinéticos (os modelos isoconversionais e o modelo de reações paralelas independentes (IPR)) para calcular a energia de ativação global de reação de pirólise de embalagens cartonadas, bem como de componentes puros, usando dados obtidos de análises termogravimétricas.

A pirólise da embalagem cartonada segue três estágios separados de desvolatilização. O primeiro passo é a perda de umidade. A segunda etapa está perfeitamente correlacionada com a desvolatilização do papel. O terceiro passo pode ser correlacionado com a desvolatilização do polietileno. A comparação entre os métodos isoconversionais de Ozawa e Starink aplicados a embalagens cartonadas, papel e ao polietileno mostram resultados semelhantes para a energia de ativação global estimada.

As energias de ativação estimadas nos dois modelos (isoconversional e IPR) apresentaram valores semelhantes aos encontrados na literatura, mesmo considerando o uso de diferentes modelos cinéticos e condições operacionais. Os modelos isoconversional e IPR foram adequados para estimar os parâmetros cinéticos da reação de pirólise da embalagem cartonada e seus componentes puros. No entanto, os métodos isoconversionais subestimaram a energia de ativação para a pirólise do polietileno. 
Melo et al. (2016) investigaram o leito de jorro cônico, como uma alternativa para a pirólise de resíduos de embalagens cartonadas. Modelaram e analisaram a dinâmica de fluidos no leito utilizando o composto de PEBD/Al compósitos e misturas de areia e composto de PEBD/Al.

Concluindo que o Modelo Multifásico Granular Euleriano (Eulerian Granular Multiphase Model) foi capaz de prever a dinâmica do fluxo no leito de jorro cônico composto por ar-PEBD/Al e ar-areia. Enquanto que, o modelo de arraste Gidaspow e de turbulência k- $\varepsilon$ disperso mostraram-se adequados para representar as características de fluxo de leitos cônicos com jorro composto de composto PEBD/Al e misturas de areia e composto PEBD/Al (de 15 a $85 \%$ em massa). Para as misturas, no regime de jorro, a modelagem usada pode estimar a queda de pressão do leito com erro de até $20 \%$.

Solak \& Rutkowski (2014) avaliaram a possibilidade de aplicação de pirólise catalítica rápida como método de reciclagem termoquímica de resíduos sólidos orgânicos. A pirólise rápida da mistura de celulose/polietileno e Tetra Pak com e sem catalisador foi realizada para determinar a influência do cloreto de metal no rendimento e na composição química dos produtos líquidos.

Os processos de pirólise da amostra das embalagens cartonadas Tetra Pak ou mistura de celulose e polietileno de baixa densidade com e sem adição de cloreto de metal foram realizados em um forno horizontal com sistema de aquecimento por infravermelho e sistema de resfriamento dinâmico. $0,2 \mathrm{~g}$ de amostra foram colocados no reator de quartzo e aquecidos até $350-500{ }^{\circ} \mathrm{C}$ com uma taxa de aquecimento de $100{ }^{\circ} \mathrm{C} / \mathrm{s}$.

A decomposição térmica de amostras de celulose/polietileno e Tetra Pak através de pirólise rápida leva à produção de bio-óleo com rendimentos de 67 a 80\%. Os resultados mostraram que a adição de $\mathrm{ZnCl}_{2}, \mathrm{CuCl}_{2}, \mathrm{AlCl}_{3}$ ou $\mathrm{FeCl}_{3}$ altera significativamente o grau de mistura de celulose/polietileno e decomposição Tetra Pak durante a pirólise rápida a $500{ }^{\circ} \mathrm{C}$. A produção de bio-óleo diminui na presença de cloreto de metal, mas a decomposição do polietileno é aprimorada e mais hidrocarbonetos líquidos são produzidos em vez de cera.

Rodríguez-Gómez et al. (2015) estudaram a recuperação do alumínio e polietileno das embalagens da Tetra Pak, utilizando um novo processo de separação, que também pode ser considerado sustentável com baixo custo de operação, utilizando a menor quantidade possível de matérias-primas e energia.

O método consiste em misturar em uma proveta de $250 \mathrm{ml}, 100 \mathrm{~g}$ de resíduos de óleo vegetal e $10 \mathrm{~g}$ de TP (amostra de resíduos Tetra Pak sem celulose) triturados, foram adicionados a $140{ }^{\circ} \mathrm{C}$ por $1 \mathrm{~h}$ com agitação por 50 min. Devido à diferença na densidade, a 
solução foi separada em duas partes: óleo com polietileno e alumínio precipitado com menos óleo e polietileno no fundo do vaso. A solução de óleo com polietileno foi filtrada e o óleo foi reutilizado para segundo e terceiro tratamentos térmicos.

O alumínio precipitado com menos óleo e polietileno permaneceu no vaso nas mesmas condições $\left(140{ }^{\circ} \mathrm{C}\right.$ por $1 \mathrm{~h}$ com agitação por $50 \mathrm{~min}$ ), e após o polietileno e o óleo serem separados e filtrados, o polietileno foi lavado com três solventes diferentes: $50 \mathrm{ml}$ de álcool etílico, $50 \mathrm{ml}$ de clorofórmio e $50 \mathrm{ml}$ de álcool isopropílico, respectivamente, e fervidos por 1 h. O alumínio obtido foi lavado com $50 \mathrm{ml}$ de álcool etílico e $50 \mathrm{ml}$ de álcool isopropílico e fervido durante $1 \mathrm{~h}$. Após lavagem dos produtos, o alumínio e o polietileno foram filtrados. Os produtos obtidos foram analisados por FTIR, análise termogravimétrica (TGA) e calorimetria diferencial de varredura (DSC). Concluindo que a porcentagem de PEBD e alumínio separado da amostra de TP foram de $85 \%$ e $80 \%$, respectivamente. O álcool isopropílico foi considerado o melhor solvente para remover o PEBD, quando comparado com outros solventes.

Rutkowski (2013) exploraram a influência da quantidade de catalisador na formação de bio-óleo durante a pirólise de embalagens de bebidas, além de desenvolverem um catalisador adequado para a pirólise de resíduos orgânicos em combustíveis líquidos.

A pirólise rápida dos resíduos com a adição de montemorilonite (K10 ou KSF) atuando como catalisador foi realizada para determinar o efeito dos parâmetros operacionais do processo na distribuição dos produtos e na composição química dos bio-óleos. A pirólise não catalítica de TA (Embalagem Tetra Pak) e a pirólise da mistura TA-KSF levam à formação de levoglucosano como principal produto líquido da decomposição do papel. Além disso, os hidrocarbonetos de cadeia longa (cera) são produzidos por decomposição térmica das camadas de polietileno. A parte orgânica do bio-óleo é composta de duas fases, ou seja, óleo polar líquido e cera.

O tipo de montemorilonite utilizado como catalisador influencia fortemente o grau de decomposição da amostra. O bio-óleo completamente líquido é produzido quando a montemorilonite K10 porosa é adicionada como um catalisador ácido à mistura de TA. O rendimento de bio-óleo atinge $65 \%$ em peso de pirólise realizada a $450{ }^{\circ} \mathrm{C}$. Como mostrado, uma quantidade crescente de catalisador promove a formação aprimorada de produtos gasosos que está relacionada às reações catalíticas secundárias.

A maior adição de montemorilonite $\mathrm{K} 10$ ao TA altera essencialmente a estrutura química dos líquidos pirolíticos. Em geral, a montemorilonite K10 catalisa transformações pirolíticas de ambos os componentes do TA, ou seja, celulose e polietileno afetando a 
(CC BY 4.0) | ISSN 2525-3409 | DOI: http://dx.doi.org/10.33448/rsd-v9i7.3827

composição do bio-óleo. No entanto, suspeita-se que durante a pirólise de TA total a atividade do catalisador diminua devido à desativação dos locais ácidos durante a transformação catalítica das camadas de celulose.

Segundo Ma (2018) nos últimos anos, o problema causado pelos resíduos da Tetra Pak (TPW) tornou-se um tópico de grande preocupação para cientistas e ambientalistas, e as empresas comerciais também começaram a se interessar pelo desenvolvimento de processos para resolver esse problema. Neste artigo, são descritos os desafios na reciclagem de TPW, através da conversão térmica, utilizando a pirólise e a carbonização hidrotérmica.

O TPW é composto por papel, polietileno e alumínio, dificultando a reciclagem devido à necessidade para separar esses diferentes compostos. Além disso, a reciclagem bemsucedida de TPW requer a construção de um ecossistema de negócios robusto. Esses problemas oferecem enormes desafios à utilização do TPW. A pirólise é uma abordagem atraente para a utilização do TPW. A decomposição do papel sob $\mathrm{N}_{2}$ levou à formação de levoglucosano e compostos fenólicos, e hidrocarbonetos de cadeia longa (cera) foram os principais produtos da pirólise do polietilieno. O produto sólido consistia em carvão e alumínio. Durante a pirólise modificada de TPW sob $\mathrm{CO}_{2}$, o carvão pode ser gaseificado por $\mathrm{CO}_{2}$ a $950{ }^{\circ} \mathrm{C}$, produzindo $\mathrm{CO}$ que pode ser usado como combustível. Alumínio manteve sua forma mesmo acima do ponto de fusão e as cinzas (principalmente $\mathrm{CaCO}_{3}$ ) pode ser facilmente separado da folha de alumínio.

\subsection{Matriz SWOT}

Desse modo, através dos dados coletados e artigos encontrados na Web of Science, foi possível identificar pontos positivos e negativos em relação ao tema de estudo (Tabela 7). 
Research, Society and Development, v. 9, n. 7, e144973827, 2020

(CC BY 4.0) | ISSN 2525-3409 | DOI: http://dx.doi.org/10.33448/rsd-v9i7.3827

Tabela 7. Matriz SWOT elaborada de acordo com as informações obtidas através dos artigos analisados no presente trabalho.

\begin{tabular}{c|c}
\hline Positivo & Negativo \\
\hline Forças & Fraquezas \\
\hline -Produção de energia renovável; & -Pequena escala de produção; \\
-Alto valor agregado. & -Poucas indústrias no ramo. \\
\hline Oportunidades & Ameaças \\
\hline -Gerenciamento dos resíduos sólidos. & -Complexidade da fluidodinâmica; \\
-Atenuar a emissão de gases do efeito & -Carência de estudos em escala \\
estufa. & industrial. \\
\hline
\end{tabular}

Fonte: Autoria Própria, 2020.

Após realização da Matriz SWOT (Tabela 7), foram obtidos os pontos positivos (forças e oportunidades) e os negativos (fraquezas e ameaças).

\section{- Forças:}

Conforme relatado por Wu e Chang (2001) e Korkmaz et al. (2009), a conversão de resíduos de embalagens cartonadas em materiais valiosos é importante do ponto de vista econômico e ambiental. Devido à obtenção de produtos de alto valor agregado, como óleos parafínicos e alumínio, além de ter um papel de destaque na redução de emissões de gases nocivos, ou de tratamento de resíduos. Surgem avanços tecnológicos, como o plasma térmico que separa o alumínio do plástico nas embalagens cartonadas. Desenvolvem-se novos processos de produção, mais sustentáveis, criam-se aplicações para os materiais descartados e cresce aceleradamente a logística reversa para os produtos pós-consumo.

\section{- Oportunidades:}

A produção de resíduos orgânicos cresceu continuamente na última década, devido a fatores como, crescimento econômico e populacional. Atualmente, um dos principais desafios enfrentados pelo mundo moderno é a utilização eficaz de resíduos orgânicos, incluindo plásticos, pneus e resíduos sólidos municipais (Haydary, et al., 2013). Dessa forma, a 
reciclagem dos resíduos Tetra Pak traz o benefício de reduzir a necessidade de material virgem e reduzir a poluição do ar (Lokahita, et al., 2017). A pirólise surge como uma tecnologia verde para separar o alumínio do polietileno, permitindo que ambas as matériasprimas possam ser usadas para a fabricação de novas embalagens cartonadas (Melo, et al., 2016). Durante o processo, diferentemente da incineração, a decomposição térmica dos materiais ocorre em atmosfera com baixo teor de oxigênio para impedir a oxidação do alumínio (Neves, 1999). Desta forma, não há combustão dos resíduos e, assim, evita-se a produção de gases de efeito estufa ou emissões tóxicas.

\section{- $\quad$ Fraquezas:}

Em detrimento ao elevado consumo, é de suma importância o estudo e aprimoramento de rotas para a recuperação dos resíduos cartonados visando sua viabilidade técnicoeconômica com consequente aplicação no País. Ainda existe um pequeno número de empresas capazes de reciclar esse tipo de matéria-prima no mundo. As empresas Alcoa, Tetra Pak, Klabin e TSL Ambiental, lançaram sua nova planta de reciclagem no Brasil em maio de 2005. É a primeira planta do mundo que pode separar e classificar os componentes usados em embalagens longa vida, através da tecnologia à plasma (Korkmaz, et al., 2009).

\section{- Ameaças:}

O reator de leito de jorro se torna um promissor reator gás-sólido para pirólise de compósito de polietileno-alumínio. Entretanto, a segregação caracterizada por concentrações heterogêneas das diferentes partículas presentes, é um fenômeno que se apresenta quando existe diferença de tamanho e/ou massa específica entre as mesmas. Tornando-se o principal desafio a ser superado antes de ser ampliado para aplicações comerciais (Marques \& Bacelos, 2013).

\section{Considerações Finais}

Através dos registros da base de dados da Web of Science (WOS) foi possível realizar uma revisão bibliométrica sobre o tema "recuperação de resíduos cartonados através da pirólise”, permitindo comparar diversos dados e estudos realizados, além de identificar as 
áreas com maiores interesses na pesquisa sobre a recuperação de resíduos cartonados através da pirólise.

Conclui-se, portanto, que as publicações sobre o tema são recentes, devido à necessidade em buscar soluções para a diminuição do impacto ambiental e gerenciamento dos resíduos sólidos, causado pelo descarte inadequado do mesmo. Além do ponto de vista ambiental, nota-se o grande interesse devido ao ponto de vista econômico, gerando produtos com alto valor agregado.

Verifica-se, a grande diversidade de estudos e pesquisas com o objetivo de encontrar/criar processos que facilitem a recuperação/reciclagem das embalagens cartonadas e que permitam ampliar as escalas de produção.

\section{Agradecimentos}

O presente trabalho foi realizado com apoio da Coordenação de Aperfeiçoamento de Pessoal de Nível Superior - Brasil (CAPES) - Código de Financiamento 001. Além disso, os autores agradecem a Federação de Amparo à Pesquisa e Inovação do Espírito Santo (FAPES), ao Conselho Nacional de Desenvolvimento Científico e Tecnológico (CNPq) e ao Programa de Pós-Graduação em Energia (PPGEN/UFES).

\section{Referências}

Alvarenga, L. M., Xavier, T. P., Barrozo, M. A. S., Bacelos, M. S., \& Lira, T. S. (2012). Analysis of reaction kinetics of carton packaging pyrolysis. Procedia Engineering, 42, 113122. https://doi.org/10.1016/j.proeng.2012.07.401

Alvarenga, L. M., Xavier, T. P., Barrozo, M. A. S., Bacelos, M. S., \& Lira, T. S. (2016). Determination of activation energy of pyrolysis of carton packaging wastes and its pure components using thermogravimetry. Waste Management, 53, 68-75. https://doi.org/10.1016/j.wasman.2016.04.015

Ang, W. L., Mohammad, A. W., Johnson, D., \& Hilal, N. (2019). Forward osmosis research trends in desalination and wastewater treatment: A review of research trends over the past 
decade. Journal of Water Process Engineering, 31, 100886.

https://doi.org/10.1016/j.jwpe.2019.100886

Bacelos, M. S., Jesus, C. D. F., \& Freire, J. T. (2009). Modeling and Drying of Carton Packaging Waste in a Rotary Dryer. Drying Technology, 27(9), 927-937.

https://doi.org/10.1080/07373930902901695

Lokahita, B., Aziz, M., Yoshikawa, K., \& Takahashi, F. (2017). Energy and resource recovery from Tetra Pak waste using hydrothermal treatment. Applied Energy, 207, 107-113. https://doi.org/10.1016/j.apenergy.2017.05.141

Berg, L., Sumner Jr, G. L., Montgomery, C. W., \& Coull, J. (1945). Naphthene Pyrolysis for Butadiene. Industrial \& Engineering Chemistry, 37(4), 352-355.

https://doi.org/10.1021/ie50424a016

Bridgwater, A. V., Meier, D., \& Radlein, D. (1999). An overview of fast pyrolysis of biomass. Organic Geochemistry, 30(12), 1479-1493. https://doi.org/10.1016/S01466380(99)00120-5

Chen, G. (2004). Electrochemical technologies in wastewater treatment. Separation and Purification Technology, 38(1), 11-41. https://doi.org/10.1016/j.seppur.2003.10.006 Cheng, H., Zhang, Y., Meng, A., \& Li, Q. (2007). Municipal solid waste fueled power generation in China: A case study of waste-to-energy in Changchun City. Environmental Science and Technology, 41(21), 7509-7515. https://doi.org/10.1021/es071416g

Czernik, S., \& Bridgwater, A. V. (2004). Overview of applications of biomass fast pyrolysis oil. Energy and Fuels, 18(2), 590-598. https://doi.org/10.1021/ef034067u

de Marco, I., Caballero, B. M., López, A., Laresgoiti, M. F., Torres, A., \& Chomón, M. J. (2009). Pyrolysis of the rejects of a waste packaging separation and classification plant. Journal of Analytical and Applied Pyrolysis, 85(1-2), 384-391.

https://doi.org/10.1016/j.jaap.2008.09.002

Freitas, T. M., Arrieche, L. S., Ribeiro, D. C., Gidaspow, D., \& Bacelos, M. S. (2017). CFD 
(CC BY 4.0) | ISSN 2525-3409 | DOI: http://dx.doi.org/10.33448/rsd-v9i7.3827

analysis of fluidized beds using wastes from post-consumer carton packaging. Chemical Engineering and Processing: Process Intensification, 111, 89-100.

https://doi.org/10.1016/j.cep.2016.12.002

Haydary, J., Susa, D., \& Dudáš, J. (2013). Pyrolysis of aseptic packages (tetrapak) in a laboratory screw type reactor and secondary thermal/catalytic tar decomposition. Waste Management, 33(5), 1136-1141. https://doi.org/10.1016/j.wasman.2013.01.03

Haydary, J., \& Susa, D. (2013). Kinetics of thermal decomposition of aseptic packages. Chemical Papers, 67(12), 1514-1520. https://doi.org/10.2478/s11696-013-0319-7

Huber, G. W., Iborra, S., \& Corma, A. (2006). Synthesis of transportation fuels from biomass: chemistry, catalysts, and engineering. Chemical reviews, 106(9), 4044-4098. https://doi.org/10.1021/cr068360d

EIA - Energy Information Administration. (2015). Independent Statistics \& Analysis. Retrieved Jan 10, 2020, from https://www.eia.gov/international/analysis/country/CHN

Jiang, Y., Ritchie, B. W., \& Benckendorff, P. (2019). Bibliometric visualisation: An application in tourism crisis and disaster management research. Current Issues in Tourism, 22(16), 1925-1957. https://doi.org/10.1080/13683500.2017.1408574

Korkmaz, A., Yanik, J., Brebu, M., \& Vasile, C. (2009). Pyrolysis of the tetra pak. Waste Management, 29(11), 2836-2841. https://doi.org/10.1016/j.wasman.2009.07.008

Li, J., \& Hale, A. (2016). Output distributions and topic maps of safety related journals. Safety Science, 82, 236-244. https://doi.org/10.1016/j.ssci.2015.09.004

Liu, H., Hong, R., Xiang, C., Lv, C., \& Li, H. (2019). Visualization and analysis of mapping knowledge domains for spontaneous combustion studies. Fuel, 262, 116598. https://doi.org/10.1016/j.fuel.2019.116598

Ma, F., \& Hanna, M. A. (1999). Biodiesel production: A review. Bioresource Technology, 70(1), 1-15. https://doi.org/10.1016/S0960-8524(99)00025-5 
Ma, Y. (2018). Changing Tetra Pak: From Waste to Resource. Science Progress, 101(2), 161170. https://doi.org/10.3184/003685018X15215434299329

Marques, I. I. D. R., \& Bacelos, M. S. (2013). Analysis of conical spouted bed fluid dynamics using carton mixtures. Chemical Engineering and Processing: Process Intensification, 70, 37-47. https://doi.org/10.1016/J.CEP.2013.05.009

Marques, I. I. D. R., Rocha, S. M. S., T.S.Lira, \& Bacelos, M. S. (2012). Air-Carton Packaging Waste Flow Dynamics in a Conical Spouted Bed. Procedia Engineering, 42, 70 79. https://doi.org/10.1016/J.PROENG.2012.07.396

Khudzari, J. M., Kurian, J., Tartakovsky, B., \& Raghavan, G. V. (2018). Bibliometric analysis of global research trends on microbial fuel cells using Scopus database. Biochemical Engineering Journal, 136, 51-60.

Melo, J. L. Z., Bacelos, M. S., Pereira, F. A. R., Lira, T. S., \& Gidaspow, D. (2016). CFD modeling of conical spouted beds for processing LDPE/Al composite. Chemical Engineering and Processing: Process Intensification, 108, 93-108.

https://doi.org/10.1016/j.cep.2016.07.011

Mohan, D., Pittman Jr, C. U., \& Steele, P. H. (2006). Pyrolysis of wood/biomass for bio-oil: a critical review. Energy \& fuels, 20(3), 848-889. https://doi.org/10.1021/ef0502397

Murray, C. B., Norris, D. J., \& Bawendi, M. G. (1993). Synthesis and Characterization of Nearly Monodisperse CdE $(\mathrm{E}=\mathrm{S}, \mathrm{Se}, \mathrm{Te})$ Semiconductor Nanocrystallites. Journal of the American Chemical Society, 115(19), 8706-8715. https://doi.org/10.1021/ja00072a025

Neves, F. L. (1999). Reciclagem de embalagens cartonadas Tetra Pak. O Papel (Brazil), $60(2), 38-45$.

Pereira, A.S. et al. (2018). Metodologia da pesquisa científica. [e-book]. Santa Maria. Ed. UAB/NTE/UFSM. Disponível em:

https://repositorio.ufsm.br/bitstream/handle/1/15824/Lic_Computacao_MetodologiaPesquisa-Cientifica.pdf?sequence=1. Acesso em: 29 Abril 2020. 
Rodríguez-Gómez, J. E., Silva-Reynoso, Y. Q., Varela-Guerrero, V., Núñez-Pineda, A., \& Barrera-Díaz, C. E. (2015). Development of a process using waste vegetable oil for separation of aluminum and polyethylene from Tetra Pak. Fuel, 149, 90-94. https://doi.org/10.1016/j.fuel.2014.09.032

Romanelli, J. P., Fujimoto, J. T., Ferreira, M. D., \& Milanez, D. H. (2018). Assessing ecological restoration as a research topic using bibliometric indicators. Ecological engineering, 120, 311-320. https://doi.org/10.1016/j.ecoleng.2018.06.015

Rutkowski, P. (2013). Characteristics of bio-oil obtained by catalytic pyrolysis of beverage carton packaging waste. Journal of Analytical and Applied Pyrolysis, 104, 609-617. https://doi.org/10.1016/j.jaap.2013.05.006

Solak, A., \& Rutkowski, P. (2014). Bio-oil production by fast pyrolysis of cellulose/polyethylene mixtures in the presence of metal chloride. Journal of Material Cycles and Waste Management, 16(3), 491-499. https://doi.org/10.1007/s10163-013-0204-z

Tetra Pak. (2020). Material de embalagem para embalagens cartonadas da Tetra Pak. Retrieved Jan 4, 2020, from https://www.tetrapak.com/packaging/materials

Van Eck, N. J., \& Waltman, L. (2010). Software survey: VOSviewer, a computer program for bibliometric mapping. Scientometrics, 84(2), 523-538. https://doi.org/10.1007/s11192-0090146-3

Whittingham, M. S. (2004). Lithium batteries and cathode materials. Chemical Reviews, 104(10), 4271-4301. https://doi.org/10.1021/cr020731c

Wu, C. H., \& Chang, H. S. (2001). Pyrolysis of tetra pack in municipal solid waste. Journal of Chemical Technology \& Biotechnology: International Research in Process, Environmental \& Clean Technology, 76(8), 779-792. https://doi.org/10.1002/jctb.404

Yang, H., Yan, R., Chen, H., Lee, D. H., \& Zheng, C. (2007). Characteristics of hemicellulose, cellulose and lignin pyrolysis. Fuel, 86(12-13), 1781-1788. 
https://doi.org/10.1016/j.fuel.2006.12.013

Yang, Y., Reniers, G., Chen, G., \& Goerlandt, F. (2019). A bibliometric review of laboratory safety in universities. Safety Science, 120, 14-24. https://doi.org/10.1016/j.ssci.2019.06.022

Ye, Z., Zhang, B., Liu, Y., Zhang, J., Wang, Z., \& Bi, H. (2014). A bibliometric investigation of research trends on sulfate removal. Desalination and Water Treatment, 52(31-33), 60406049. https://doi.org/10.1080/19443994.2013.812991

Zakzeski, J., Bruijnincx, P. C. A., Jongerius, A. L., \& Weckhuysen, B. M. (2010). The catalytic valorization of lignin for the production of renewable chemicals. Chemical Reviews, 110(6), 3552-3599. https://doi.org/10.1021/cr900354u

Zhang, S. B., Wei, S. H., \& Zunger, A. (2001). Intrinsic n-type versus p-type doping asymmetry and the defect physics of ZnO. Physical Review B, 63(7), 075205. https://doi.org/10.1103/PhysRevB.63.075205

\section{Porcentagem de contribuição de cada autor no manuscrito}

Diunay Zuliani Mantegazini - 60\%

Thiago Padovani Xavier - 20\%

Marcelo Silveira Bacelos - 20\% 